NBER WORKING PAPER SERIES

\title{
WAGES AND EMPLOYMENT: THE CANONICAL MODEL REVISITED
}

\author{
Audra Bowlus \\ Eda Bozkurt \\ Lance Lochner \\ Chris Robinson \\ Working Paper 24069 \\ http://www.nber.org/papers/w24069 \\ NATIONAL BUREAU OF ECONOMIC RESEARCH \\ 1050 Massachusetts Avenue \\ Cambridge, MA 02138 \\ November 2017
}

This work was supported by the Centre for Human Capital and Productivity at the University of Western Ontario and the Canadian Social Sciences and Humanities Research Council. The views expressed herein are those of the authors and do not necessarily reflect the views of the National Bureau of Economic Research.

NBER working papers are circulated for discussion and comment purposes. They have not been peer-reviewed or been subject to the review by the NBER Board of Directors that accompanies official NBER publications.

(C) 2017 by Audra Bowlus, Eda Bozkurt, Lance Lochner, and Chris Robinson. All rights reserved. Short sections of text, not to exceed two paragraphs, may be quoted without explicit permission provided that full credit, including $(\odot$ notice, is given to the source. 
Wages and Employment: The Canonical Model Revisited

Audra Bowlus, Eda Bozkurt, Lance Lochner, and Chris Robinson

NBER Working Paper No. 24069

November 2017

JEL No. J24,J31

\begin{abstract}
$\underline{\text { ABSTRACT }}$
The basic canonical model fails to predict the aggregate college premium outside of the original sample period (1963-1987) or to account for the observed deviations in college premia for younger vs. older workers. This paper documents that these failings are due to mis-measurement of the relevant prices and quantities when using composition adjustment methods to construct relative skill prices and supplies, which ignore cohort effects that are particularly important in the 1980s and 1990s. Re-estimating the model with prices and quantities that incorporate cohort effects produces a good fit for the out of sample prediction and explains the observed deviation in the college premium for younger vs. older workers even with perfect substitutability across age. Moreover, the estimated elasticity of substitution between high and low skill is higher and there is a much smaller role for skill-biased technical change in explaining the path of the college wage premium. The elasticity of substitution is also an important parameter for the broader literature on education and wages, especially in assessing general equilibrium responses to government policies. In the case of a tuition subsidy, price responses can undo most of the direct (partial equilibrium) effect of the subsidy on enrolment, so that general equilibrium enrolment responses are substantially weaker. The higher elasticity estimated in this paper, produces much weaker general equilibrium relative price changes and stronger enrolment effects.
\end{abstract}

Audra Bowlus

University of Western Ontario

London, Ontario, Canada N6A 5C2

abowlus@uwo.ca

Eda Bozkurt

Department of Economics

University of Western Ontario

1151 Richmond St. N.

London, ON, N6A 5C2

Canada

ebozkurt@uwo.ca
Lance Lochner

Department of Economics

Faculty of Social Science

Western University

1151 Richmond Street, North

London, ON N6A 5C2

CANADA

and NBER

llochner@uwo.ca

Chris Robinson

University of Western Ontario

London, Ontario, Canada N6A 5C2

robinson@uwo.ca 


\section{Introduction}

A simple supply-demand framework has formed the basis of a large body of research on the determinants of wages and employment in the post-war US economy. The basic framework, used most notably in Katz and Murphy (1992) and termed the "canonical model" in Acemoglu and Autor (2011), considers two broad types of skills - low (i.e. high school) and high (i.e. college) skill - in which relative prices (and quantities) of the skills are determined in equilibrium. The primary aim of this literature has been to understand the extent to which supply and demand factors, especially technological changes, have influenced the evolution of the "skill premium", motivated in large part by the dramatic rise in wages among skilled relative to unskilled workers over a sustained period of increases in the supply of skilled labor.

Two features of aggregate productivity play leading roles in the canonical supply-demand framework: the productivity of skilled relative to unskilled workers and the substitutability between skilled and unskilled labor inputs. The literature on skill-biased technological change (SBTC) emphasizes the evolution of relative productivity levels (Katz and Murphy (1992), Heckman, Lochner and Taber (1998), Katz and Autor (1999) , Card and Lemieux (2001), Autor, Katz and Kearney (2008), Acemoglu and Autor (2011)), while the literature studying the general equilibrium effects of government policy relies heavily on the elasticity of substitution (Heckman, Lochner and Taber (1998a), Heckman, Lochner and Taber (1998b), Abbott, et al (2013), Lee and Wolpin (2006)).

Estimating these key features of the production technology requires accurate and consistent measures of relative skill prices and aggregate skill inputs over time. The standard approach employs a simple composition adjustment to account for changes in the composition of each broad skill type (high vs. low) based on such observable characteristics as educational attainment, age or experience, and gender; however, it does not account for changes in the productivity of workers within each of these narrow categories. That is, it assumes that a 30-35 year-old male college graduate in 2000 provides the same effective skilled labor input as his counterpart from 1970, effectively ignoring any changes in the selection of individuals into college or advances in the production of human capital over time. As demonstrated in Bowlus and Robinson (2012), this assumption is unlikely to be true, leading to gross mis-measurement of the time trends of relative skill prices and labor inputs.

This paper builds on the approach of Bowlus and Robinson (2012) and Heckman, Lochner and Taber (1998) to better measure the evolution of relative skill prices and inputs when the skill levels 
of workers are changing across cohorts. Using these improved measures, this paper re-estimates the canonical model, providing new estimates of SBTC and the elasticity of substitution across skilled and unskilled labor. Interestingly, this more general measurement approach helps resolve a number of puzzles raised in previous studies (Card and Lemieux (2001, Acemoglu and Autor (2011)) regarding the canonical model and its predictions, lending greater legitimacy to the simple supplydemand framework favored by much of the literature. The new estimates of technological change suggest a more muted role for SBTC than previous estimates of the same canonical model based on composition adjusted wage and skill measures that neglect cohort effects. ${ }^{1}$ Our estimates of the elasticity of substitution between skilled and unskilled labor are higher than previous studies (based on simple composition adjustments) suggesting that equilibrium price changes in response to policy shifts are likely to be weaker than previously thought.

As Acemoglu and Autor (2011) note, estimates of the canonical model using composition adjusted wages and skill supplies (assumed to be exogenously determined by demographic factors) and a linear trend representing SBTC fits the evolution of the skill premium in the US remarkably well over the 1963-1987 period as studied by Katz and Murphy (1992). These estimates suggest a significant role for SBTC and a low elasticity of substitution between high school and college labor, $\sigma$, that ranges from 1.4 to $1.8 .^{2}$ Unfortunately, major problems arise in identifying SBTC-induced demand changes and the value of $\sigma$ when the model is estimated over a longer time horizon (using simple composition adjusted wages and supplies). Examining the performance of the model from 1963 to 2008, Acemoglu and Autor (2011) document poor out of sample predictions when using parameters estimated on the original Katz and Murphy (1992) period (1963-1987) to predict the college premium after 1987. They further document wildly varying estimates of $\sigma$ when the extended period of data is used. Finally, if a more flexible time trend is used to improve the fit over the full 1963-2008 period and to stabilize estimates of the elasticity of substitution, the implied time path for SBTC is inconsistent with other direct evidence from, for example, expansions in computer use.

A further problem with the standard implementation of the canonical model emphasized by Card and Lemieux (2001) is its failure to explain differences in the paths of skill premia over time

\footnotetext{
${ }^{1}$ Card and DiNardo (2002), Eckstein and Nagypal (2004) and Lemieux (2006) raise other concerns about the extent to which SBTC can explain the broad trends in wage inequality over the past few decades.

${ }^{2}$ Estimates from this literature suggest a major role for SBTC when estimated directly as linear trend changes in production function parameters following the approach of Katz and Murphy (1992) or indirectly through capital-skill complementarity coupled with increases in capital (Krusell, et al (2000)).
} 
for different age groups. In particular, Card and Lemieux (2001) note that the rapid rise in the skill premium from 1975-1995 was largely confined to younger workers. They address this problem by disaggregating labor input groups by age and allowing for imperfect substitutability across these age and skill groups; however, this resolution detracts from the simplicity of the canonical framework.

The primary contribution of this paper is to show that many of these 'problems' with the canonical model are due to measurement problems and not the underlying economic framework. In particular, the standard composition adjustment procedure fails to account for important cohort changes in the skill levels of workers within narrowly defined age-sex-education cells that compose each broad skill type. The work of Heckman, Lochner and Taber (1998), Carneiro and Lee (2011), Bowlus and Robinson (2012) and Hendricks and Schoellman (2014) draws attention to the distinction between relative skill prices and relative wages. Recognizing that human capital investments decline to zero near the end of workers' careers, Heckman, Lochner and Taber (1998) show that it is possible to identify changes in skill prices from changes in wages for older workers. Applying this methodology, Bowlus and Robinson (2012) (henceforth, BR) show that over the 1963-2008 period, there is a large difference in the behavior of composition adjusted relative wages and relative skill prices. ${ }^{3}$

Using the BR prices and quantities in place of the standard composition adjusted measures, there is no significant out-of-sample prediction problem when parameters estimated on the 1963-87 period of Katz and Murphy (1992) are used to predict the evolution of relative skill prices over the following decades (1988-2008). Since composition adjusted relative wages - the conventional skill premium - remains a measure of great interest, an augmented version of the canonical model with BR-estimated quantities is developed to explain the path of relative wages in terms of a part due to changes in relative prices and a part due to changes in relative skill levels (i.e. the amount of human capital supplied by the typical college graduate relative to the amount supplied by the typical high school graduate). SBTC is relevant for the first, but not the second. A decomposition shows that relative price changes and, therefore, SBTC are much less important than suggested by the previous literature. Furthermore, the difference in relative college and high school skill levels across cohorts fully explains the observed evolution of relative wages by age, suggesting little need to differentiate

\footnotetext{
${ }^{3} \mathrm{BR}$ refer to this as the "flat-spot" method. Using estimated price series from this approach, they estimate human capital profiles that vary substantially across cohorts due to selection in education choice and technological change in human capital production. Using a very different methodology, Carneiro and Lee (2011) directly estimate selection effects and find similar variation in 'quality' among college graduates from different birth cohorts based on their enrolment rates.
} 
skill groups further by age as in Card and Lemieux (2001). ${ }^{4}$

The elasticity of substitution not only plays an important role in determining the effects of SBTC, but it is also an important parameter for the broader literature on education and wages, especially in assessing general equilibrium responses to government policies due to changes in relative skill prices. For example, the relatively low elasticity of substitution estimated in previous studies of the canonical model (using composition adjusted prices) implies large skill price responses to any change in the skill composition of the economy. In the case of a tuition subsidy, these price responses undo much of the direct (partial equilibrium) effect of the subsidy on enrolment, so that general equilibrium enrolment responses are substantially weaker (Heckman, Lochner and Taber (1998b)). By contrast, the higher elasticities obtained when accounting for cohort differences in skill levels (as estimated by BR) produce much weaker general equilibrium relative price changes and stronger enrolment effects.

The structure of the paper is as follows. Section 2 briefly summarizes the canonical model and introduces the distinction between relative prices and composition adjusted relative wages. Section 3 contrasts estimates of the canonical model based on skill prices and quantities as derived in BR with those obtained from the standard composition adjusted wages and quantities as in, e.g., Katz and Murphy (1992) or Acemoglu and Autor (2011). This section demonstrates that when prices and quantities that generally account for cohort differences are used, the canonical model with a linear trend fits the evolution of the skill premium over the entire 1963-2008 period quite well. The estimates imply a much higher elasticity of substitution and a much smaller role for SBTC.

Section 4 extends the analysis to the disaggregated canonical model introduced by Card and Lemieux (2001) to explain the age or experience pattern in relative (composition adjusted) wages. The results show that when relative quantities for the different experience groups are adjusted to take into account cohort effects, the qualitative patterns in composition adjusted relative wages across experience groups can be reproduced, substantially reducing the need to introduce imperfect substitutability across age or experience groups in the canonical model.

The use of standard composition adjusted measures results in a much lower value for $\sigma$ than is

\footnotetext{
${ }^{4}$ A comparison of the US, UK and Canada also presents challenges for the canonical model. In particular, Card and Lemieux (2001) estimate very different trends in SBTC and the elasticity of substitution for Canada compared to the US and UK, despite the fact that the US and Canadian economies are more economically integrated and similar than those of the US and UK. Accounting for cohort differences in relative skills, Bowlus, Liu and Robinson (2017) estimate different relative price and quantity paths for Canada and the US, which helps reconcile this puzzle.
} 
obtained when the measures are corrected for cohort effects. Section 5 provides two examples of the importance of $\sigma$ in the context of endogenous relative supplies. First it documents the sensitivity of SBTC estimates to alternative values for $\sigma$ within the framework of the canonical model, but relaxing the assumption of exogenous relative supplies. Second, it contrasts the partial and general equilibrium effects and shows the sensitivity of the general equilibrium effect to the value of $\sigma$.

Finally, Section 6 provides some conclusions.

\section{Estimation of the Canonical Model}

In this section, we formally describe the canonical model and the frequently estimated relative wage (or skill premium) equation, pointing out the important roles played by SBTC and the elasticity of substitution between skill types. We also discuss the distinction between observed wages and actual skill prices, and the implications of this distinction and cohort variation in average worker quality (or human capital) for estimation of the canonical model.

\subsection{The Standard Two Skill Type Model}

The canonical model assumes competitive labor markets with two imperfectly substitutable skill types, high and low. The total supplies of aggregate low and high skill inputs to production are, respectively:

$$
\begin{aligned}
L & =\int_{i \in \mathcal{L}} l_{i} n_{i} d i \\
H & =\int_{i \in \mathcal{H}} h_{i} n_{i} d i
\end{aligned}
$$

where $l_{i}\left(h_{i}\right)$ reflect the efficiency units (or human capital) supplied each hour and $n_{i}$ reflects total hours worked for worker $i \in \mathcal{L}(\in \mathcal{H})$. The aggregate production function is of the CES form:

$$
Y=\left[\left(A_{L} L\right)^{\frac{\sigma-1}{\sigma}}+\left(A_{H} H\right)^{\frac{\sigma-1}{\sigma}}\right]^{\frac{\sigma}{\sigma-1}}
$$

where $A_{L}$ and $A_{H}$ reflect technology constants that determine the productivity of low and high skill labor inputs, respectively and $\sigma \geq 0$ reflects the elasticity of substitution between the two skill types. Factor-augmenting technical change is captured by changes over time in $A_{L}$ and $A_{H}$.

The competitive labor market assumption implies that firms will set the value of the marginal 
products of $L$ and $H$ equal to the unit wage, or price per efficiency unit of each type of skill:

$$
\begin{aligned}
& \frac{\partial Y}{\partial L}=A_{L}^{\frac{\sigma-1}{\sigma}}\left[\left(A_{L} L\right)^{\frac{\sigma-1}{\sigma}}+\left(A_{H} H\right)^{\frac{\sigma-1}{\sigma}}\right]^{\frac{1}{\sigma-1}} L^{\frac{-1}{\sigma}}=w_{L} \\
& \frac{\partial Y}{\partial H}=A_{H}^{\frac{\sigma-1}{\sigma}}\left[\left(A_{L} L\right)^{\frac{\sigma-1}{\sigma}}+\left(A_{H} H\right)^{\frac{\sigma-1}{\sigma}}\right]^{\frac{1}{\sigma-1}} H^{\frac{-1}{\sigma}}=w_{H} .
\end{aligned}
$$

As discussed further below, it is important to recognize that these skill prices, $w_{L}$ and $w_{H}$, differ from the corresponding hourly wages received by workers given by $w_{L} l_{i}$ and $w_{H} h_{i}$, respectively.

Combining equations (2) and (3) and taking logs yields the relative demand function:

$$
\ln (H / L)=(\sigma-1) \ln \left(A_{H} / A_{L}\right)-\sigma \ln \left(w_{H} / w_{L}\right)
$$

Relative demand depends on a technology component $(\sigma-1) \ln \left(A_{H} / A_{L}\right)$, which may evolve over time due to SBTC, and relative skill prices. The elasticity of substitution determines both the slope of the demand function, $-\sigma$, with respect to relative prices, as well as the importance of changes in technology.

Equation (4) may be re-arranged to yield the well-known skill premium equation:

$$
\ln \omega=\ln \left(w_{H} / w_{L}\right)=\frac{\sigma-1}{\sigma} \ln \left(A_{H} / A_{L}\right)-\frac{1}{\sigma} \ln (H / L) .
$$

This equation clearly shows that even in an era of secular increases in the supply of skilled labor (i.e. increases in $H / L)$, the skill premium can increase if relative demand shifts at a faster pace. This is often characterized as a race between education (supply shifts) and technology (demand shifts)..$^{5}$ As emphasized in Goldin and Katz (2007) and evident from equation (5), the elasticity of substitution plays a critical role in this race. The larger is $\sigma$ the greater the impact of changes in technology $\left(A_{H} / A_{L}\right)$ on the skill premium, while the opposite is true for changes in relative skill supplies $(H / L)$. Intuitively, as high and low skilled workers become closer substitutes, the skill premium becomes less sensitive to any change in relative supplies and more responsive to any SBTC-induced demand shifts.

\subsection{Relative Prices, Relative Wages and Composition Adjustments}

The canonical model, encapsulated in equation (5), applies directly to relative skill prices, $w_{H} / w_{L}$, and aggregate relative skill supplies, $H / L$. However, neither of these are directly observed by re-

\footnotetext{
${ }^{5}$ See, for example, Acemoglu and Autor (2011) and Goldin and Katz (2007) who attribute the first use of the phrase to Tinbergen (1974).
} 
searchers. When there is on-the-job investment of the form discussed in Becker (1964) and BenPorath (1967), it is particularly difficult to separate the price of skill from the individual supply of human capital since both may change over time. As noted by Heckman, Lochner and Taber (1998) and BR, this challenge can be overcome by looking at older workers whose skills stop evolving as they stop investing in their human capital. Changes in skill prices can, therefore, be identified (up to a scale normalization in one period) from changes in their wages. Aggregate low and high skill supplies, $L_{t}$ and $H_{t}$, can then be obtained each period by dividing the total low and high wage bills, $W_{L t}=w_{L t} L_{t}$ and $W_{H t}=w_{H t} H_{t}$ by the respective estimated skill prices that period, $w_{L t}$ and $w_{H t}$. Our direct approach to estimating equation (5) uses relative skill prices and aggregate supplies obtained by BR using this procedure.

This approach to measuring aggregate skill supplies is not typically taken by the literature. ${ }^{6}$ Instead, most previous studies (Katz and Murphy (1992), Katz and Autor (1999), Card and Lemieux (2001), Autor, Katz and Kearney (2008), Acemoglu and Autor (2011)) employ a composition adjustment approach, which takes into account changes in the composition of the workforce with respect to age, gender and educational attainment, but implicitly assumes that average human capital levels for workers in these observable groups do not change over time. Specifically, let $\bar{l}_{j t}\left(\bar{h}_{j t}\right)$ be the average level of low (high) skill for all workers $i \in \mathcal{L}_{j}\left(i \in \mathcal{H}_{j}\right)$ in period $t$, where $\mathcal{L}_{j}\left(\mathcal{H}_{j}\right)$ reflect different subsets or cells of workers defined by age, gender and educational attainment (e.g. high school dropouts and graduates are typically included in $\mathcal{L}$, while workers with some college, college degrees and beyond are included in $\mathcal{H}) .{ }^{7}$ The aggregate supplies of low and high skilled labor are given by:

$$
\begin{aligned}
L_{t} & =\sum_{j \in \mathcal{J}_{L}} n_{j t} \bar{l}_{j t} \\
H_{t} & =\sum_{j \in \mathcal{J}_{H}} n_{j t} \bar{h}_{j t},
\end{aligned}
$$

where $n_{j t}$ is the number of person hours in cell $j$ at time $t$ and $\mathcal{J}_{L}$ and $\mathcal{J}_{H}$ reflect the set of all low and high skill subgroups, respectively. The composition adjustment approach assumes that $\bar{l}_{j t}=\bar{l}_{j}$ $\left(\bar{h}_{j t}=\bar{h}_{j}\right)$ is constant over time so the composition adjusted aggregate supplies of low and high

\footnotetext{
${ }^{6}$ Heckman, Lochner and Taber (1998) is a notable exception.

${ }^{7}$ Workers with some college are often allocated partially to each broad skill group. This does not affect the current discussion.
} 
skilled labor are, respectively, given by:

$$
\begin{aligned}
L_{c t} & =\sum_{j \in \mathcal{J}_{L}} n_{j t} \bar{l}_{j} \\
H_{c t} & =\sum_{j \in \mathcal{J}_{H}} n_{j t} \bar{h}_{j} .
\end{aligned}
$$

The $n_{j t}$ are directly observed from the hours measures for each cell. However, the $\bar{l}_{j}$ and $\bar{h}_{j}$ have to be estimated. In most previous studies using the composition adjustment approach, these are estimated as follows. First, all worker hours are assigned to cells according to the detailed education and experience level of the worker, as well as some demographic characteristics, such as male or female. Second, the cells are assigned to high or low skill, based on the education level for the cell. Third, for all the cells in each of the high and low groups, the real hourly wage for each cell in the group, averaged over the full period of the sample, is calculated and a "base" cell for each skill type is defined (e.g. high school graduates with 1-5 years of experience). Fourth, the relationship between the quantity of each cell in the high or low group, relative to the base cell for the skill type, is then estimated by the ratio of the average real hourly wage for each cell relative to the base cell. ${ }^{8}$

While the composition adjustment approach accounts for effects on skill supplies as a result of composition changes $\left(n_{j t}\right)$ over time, it does not account for changes over time within cells $\left(\bar{l}_{j t}\right.$ and $\bar{h}_{j t}$ ). If cohort effects lead to changes in the average human capital supplied by workers within cells over time, then the time path of the composition adjusted supplies will not generally be the same as the time path of the true aggregate skill supplies. Indeed, BR document substantial differences in the evolution of these composition adjusted measures and true aggregate stocks of skill that take into account cohort effects, i.e. that do not impose $\bar{l}_{j t}=\bar{l}_{j}$ and $\bar{h}_{j t}=\bar{h}_{j}$.

To incorporate these differences across cohorts in the canonical model, define the time-varying constants $B_{L t}=L_{t} / L_{c t}$ and $B_{H t}=H_{t} / H_{c t}$. A normalization is required for comparison of $L_{t}\left(H_{t}\right)$ and $L_{c t}\left(H_{c t}\right)$. Let $\bar{l}_{j}$ and $\bar{h}_{j}$ be the the long run average of the $\bar{l}_{j t}$ and $\bar{h}_{j t}$, respectively. With this normalization, $B_{L t}$ and $B_{H t}$ reflect the $\left(n_{j t}\right.$ weighted) deviations of the $\bar{l}_{j t}$ and $\bar{h}_{j t}$ from their long run average over the full data period. ${ }^{9}$ If, on average across all low (high) skill cells, there was an increase in the average amount of skill supplied per worker hour, this would be reflected in an increase in $B_{L t}\left(B_{H t}\right)$ over time.

\footnotetext{
${ }^{8}$ See Autor, Katz and Kearney (2008), Acemoglu and Autor (2011) for more details.

${ }^{9}$ Define the deviation $l_{j t}^{d}=\bar{l}_{j t}-\bar{l}_{j}$, where $\bar{l}_{j}=\sum_{t=1}^{T} n_{j t} \bar{l}_{j t} / \sum_{t=1}^{T} n_{j t}$. Then $L_{t}=\sum_{j \in \mathcal{J}_{L}} n_{j t} \bar{l}_{j t}=\sum_{j \in \mathcal{J}_{L}} n_{j t}\left(\bar{l}_{j}+\right.$ $\left.l_{j t}^{d}\right)=L_{c t}+\sum_{j \in \mathcal{J}_{L}} n_{j t} l_{j t}^{d}$ and $B_{L t}=1+\left(1 / L_{c t}\right) \sum_{j \in \mathcal{J}_{L}} n_{j t} l_{j t}^{d}$. When $\sum_{j \in \mathcal{J}_{L}} n_{j t} l_{j t}^{d}=0, B_{L t}=1$.
} 
Since the total wage bill for a skill type is the product of the skill price and the skill quantity, the implied composition adjusted wages are simply $w_{L t}^{c}=W_{L t} / L_{c t}=B_{L t} w_{L t}$ and $w_{H t}^{c}=W_{H t} / H_{c t}=$ $B_{H t} w_{H t} .{ }^{10}$ Notice that composition adjusted wages differ from actual skill prices whenever average human capital levels within different subgroups vary across cohorts.

Substituting the composition adjusted terms into (5), using $B_{L t}$ and $B_{H t}$, the skill premium equation can be re-written in terms of composition adjusted wages and supplies:

$$
\ln \omega_{c t} \equiv \ln \left(w_{H t}^{c} / w_{L t}^{c}\right)=\frac{\sigma-1}{\sigma} \ln \left(A_{H t} / A_{L t}\right)+\frac{\sigma-1}{\sigma} \ln \left(B_{H t} / B_{L t}\right)-\frac{1}{\sigma} \ln \left(H_{c t} / L_{c t}\right),
$$

where $\ln \left(B_{H t} / B_{L t}\right)$ accounts for potential discrepancies between composition adjusted measures and true measures of skill prices and aggregate supplies. Note that the term $\ln \left(B_{H t} / B_{L t}\right)$ plays exactly the same role in determining the composition adjusted wage premium, $\ln \omega_{c}$, as the SBTC term, $\ln \left(A_{H t} / A_{L t}\right)$. However, they reflect very different economic forces: the former reflects changes in the relative human capital per worker of skilled vs. unskilled workers, while the latter reflects changes in relative demand due to technology shifts in production. That is, the workers of each skill type, but from different cohorts vary in the amount of efficiency units they supply within a given time period and a given production function and $\ln \left(B_{H t} / B_{L t}\right)$ reflects these cohort effects as the cohort makeup of the labor force changes over time. In contrast, $\ln \left(A_{H t} / A_{L t}\right)$ captures changes in the production function.

Most studies do not include the adjustment term $\ln \left(B_{H t} / B_{L t}\right)$ in estimating equation (10), ignoring changes in relative human capital per worker (within age-gender-education groups), and instead attribute these changes to SBTC. As shown below, average human capital per worker has increased more for high relative to low skilled workers, causing previous studies to overstate the importance of SBTC in explaining the skill premium. We refer to equation (10) as the augmented canonical model.

\section{Empirical Implementation of the Canonical Model}

Identifying the relative importance of demand and supply shifts in determining the path of the skill premium is complicated by the fact that, while various measures of the skill premium and the relative supply variable are available, the variable relevant for demand intercept shifts or SBTC,

\footnotetext{
${ }^{10}$ The previous literature typically computes the composition adjusted wages using an alternative procedure to adjust for composition changes with data restricted to high school graduates and college graduates only. The relative wage series obtained are similar, as internal consistency requires.
} 
$\ln \left(A_{H t} / A_{L t}\right)$, is not. In addition, relative supply may not be exogenous. The most common approach in the literature assumes exogenous supplies and a parametric time trend for $\ln \left(A_{H t} / A_{L t}\right)$, estimating both SBTC and $\sigma$ from data on composition adjusted relative wages and skill supplies (Katz and Murphy (1992), Card and Lemieux (2001), Autor, Katz and Kearney (2008), Acemoglu and Autor (2011)). ${ }^{11}$ In practice, these studies typically estimate equation (10) under the implicit assumption that $\ln \left(B_{H t} / B_{L t}\right)$ does not change over time (i.e. there is no cohort variation in average within cell relative human capital levels).

If an estimated series for $\ln \left(B_{H t} / B_{L t}\right)$ is available, it can be included in equation (10) (i.e. the augmented canonical model) to account for cohort differences in worker human capital levels. This model can be estimated with the same composition adjusted relative wage and supply series used in the standard literature. Assuming exogenous supplies and a parametric time trend for SBTC, both $\sigma$ and SBTC effects can be estimated from equation (10). An alternative approach is to estimate equation (5) directly using estimates of actual skill prices $\left(w_{L t}, w_{H t}\right)$ and supplies $\left(H_{t}, L_{t}\right)$, as in $\mathrm{BR}$, that account for differences in human capital levels (within narrowly defined subgroups) across cohorts. ${ }^{12}$ This enables estimation of both demand and supply effects on the evolution of relative prices, $\ln \omega_{t}$. If desired, these estimates can then be combined with the path of $\ln \left(B_{H t} / B_{L t}\right)$ to generate relative wage paths, $\ln \omega_{c t}$, which can be decomposed into supply effects, demand effects (i.e. SBTC), and changes in relative worker quality.

\subsection{Data and Construction of the Variables}

To estimate the canonical model, we use the same data as BR from the March CPS over earnings years 1963-2008. ${ }^{13}$ These data are very similar to those used by Acemoglu and Autor (2011) in their replication of Katz and Murphy (1992) and in their extension to 2008.

We follow the literature in defining skill types according to the educational attainment of work-

\footnotetext{
${ }^{11}$ The literature has taken two main approaches to modelling supply. One approach assumes only that the observations are on the demand curve and uses a constant "reasonable" value of $\sigma$ obtained from "the literature", together with observations on $\ln (H / L)$ and $\ln \omega$, to back out the implied SBTC from equation (5) using various sub-periods of the data (Goldin and Katz (2007), Autor, Levy and Murnane (2003)). Card and DiNardo (2002), noting the tautological nature of an unrestricted SBTC hypothesis, discuss a third approach that uses a proxy for the unobserved demand shifts, typically related to computer use. Krusell et al (2000) explore a capital-skill complementarity hypothesis and measures of capital over time to provide more direct measures of the demand shift.

${ }^{12}$ Note that this approach would be equivalent to the standard approach using composition adjusted relative wages and supplies if $B_{H t} / B_{L t}$ were constant over time (normalized to one), since then $\ln \omega_{t}=\ln \omega_{c t}$ and $\ln \left(H_{t} / L_{t}\right)=$ $\ln \left(H_{c t} / L_{c t}\right)$.

${ }^{13}$ We apply individual year top-code correction factors as in BR.
} 
ers. The literature typically begins with four education groups (high school dropouts, high school graduates, some college, and college graduates) and collapses them into two broad skill "types": the high skilled (i.e. college graduate) type and the low skilled (i.e. high school graduate) type. In creating aggregate skill supplies, most studies allocate all college graduate cell hours and $50 \%$ of some college cell hours to the high skill type and the remainder to the low skill type. In constructing relative composition adjusted wages, only college graduate and high school graduate wages are typically used to calculate $w_{H}^{c}$ and $w_{L}^{c}$, respectively. ${ }^{14}$ We use the definitions specified in Autor, Katz and Kearney (2008) and used in Acemoglu and Autor (2011) to construct composition adjusted relative wage ratios, $\ln \omega_{c}$, and supplies, $\ln \left(H_{c} / L_{c}\right)$, representative of the literature. As noted earlier, these measures are not necessarily the same as true relative prices and supplies, $\ln \omega$ and $\ln (H / L)$, if average human capital levels within age-gender-schooling cells have changed.

Carneiro and Lee (2011), BR, and Hendricks and Schoellman (2014) provide evidence that $\ln \left(B_{H} / B_{L}\right)$ varies over time, especially over the period of the rapidly rising wage premium. Carneiro and Lee (2011) and Hendricks and Schoellman (2014) attribute this primarily to variation in the quality of college graduates across birth cohorts linked to their enrolment rates. BR allow for these selection effects as well as secular changes in human capital production, especially at the college level, that might reflect advancements in knowledge or education. We construct a series for $\left(B_{H} / B_{L}\right)$ using a comparison of the quantity ratios, $(H / L)$ and $\left(H_{c} / L_{c}\right)$. The ratio $(H / L)$ is obtained by dividing the ratio of the total wage payments, $\left(W_{H} / W_{L}\right)$, by the price ratio $\left(w_{H} / w_{L}\right)$, estimated using the BR prices. ${ }^{15}$ The ratio $\left(H_{c} / L_{c}\right)$ is constructed as in Autor, Katz and Kearney (2008). ${ }^{16}$

\subsection{Relative Prices, Wages, and Supplies: 1963-2008}

Figure 1 shows the path of relative composition adjusted wages, $\ln \omega_{c t}$, and relative prices, $\ln \omega_{t}$, over the 1963-2008 period. For comparison purposes, the relative price series from $\mathrm{BR}, \ln \omega_{t}$, is

\footnotetext{
${ }^{14}$ See Autor, Katz and Kearney (2008) for details.

${ }^{15} \mathrm{BR}$ calculate four price series for four education groups, college graduates, some college, high school graduates and high school dropouts. To match the approach in Autor, Katz and Kearney (2008) and Acemoglu and Autor (2011) where only college and high school graduates are used to compute the composition adjusted high and low skill prices, we use the BR series for college graduates for the high skill price and high school graduates series for the low skill price.

${ }^{16}$ The $\ln \left(B_{H} / B_{L}\right)$ series can be calculated from a comparison of estimates of the log quantity $\operatorname{ratios}, \ln (H / L)$ and $\ln \left(H_{c} / L_{c}\right)$, or from log price ratios, $\ln \omega$ and $\ln \omega_{c}$. In theory, these should yield the same values for $\ln \left(B_{H} / B_{L}\right)$; however, as noted above, most studies do not obtain estimates of $w_{L}^{c}$ and $w_{H}^{c}$ by dividing total wage payments to low and high skilled workers by the composition adjusted stocks $L_{c}$ and $H_{c}$. As a result, estimated series for $\ln \left(B_{H} / B_{L}\right)$ will generally differ depending on whether they are obtained from comparing relative composition adjusted wages/prices or skill supplies. In practice, we find only minor differences.
} 


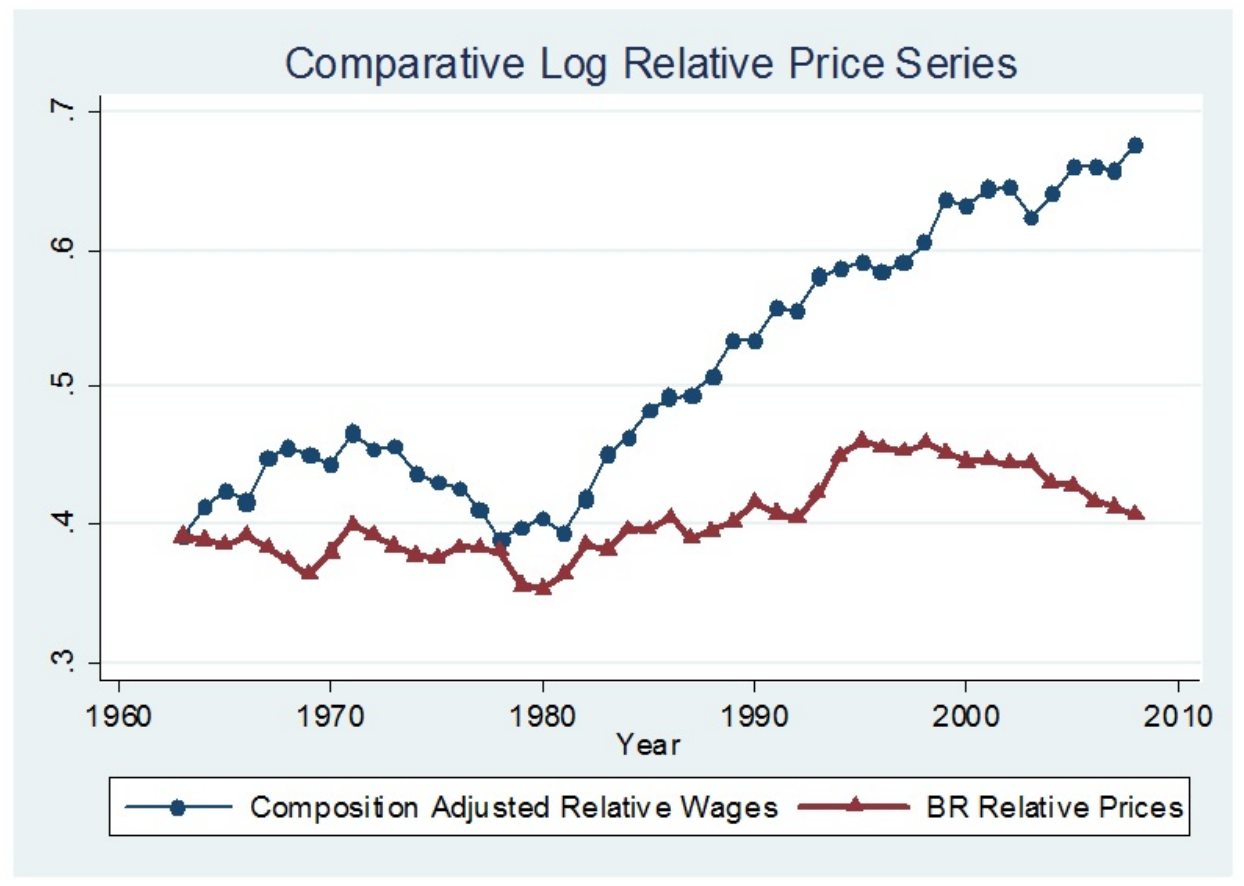

Figure 1

normalized to the same initial (1963) value as $\ln \omega_{c t}$. The two series show a fall from the early to mid-1970s to the late 1970s, followed by a strong secular increase up to the late 1990s. Explaining the turnaround in relative prices/wages in the early 1980s followed by a period of sustained increases due to supply increases with a simple linear time trend in SBTC is considered a key success of the canonical model. However, there are major differences between the paths for $\ln \omega_{t}$ and $\ln \omega_{c t}$, with the difference between these two series reflecting changes in the relative "quality" of college graduates compared to high school graduates, $\ln \left(B_{H t} / B_{L t}\right)$.

The path of $\ln \left(B_{H t} / B_{L t}\right)$ over time is plotted in Figure 2. After the mid-1970s the relative quality of college graduates compared to high school graduates increases over time. The pattern of increasing per capita efficiency units for college graduates over this period is consistent with findings in Carneiro and Lee (2011), BR, and Hendricks and Schoellman (2014). The implied rise in $\ln \left(B_{H t} / B_{L t}\right)$ and modest increase in $\ln \omega_{t}$ suggests that much of the increase in the observed skilled wage premium is likely due to an increase in the relative quality of skilled workers rather than SBTC. 


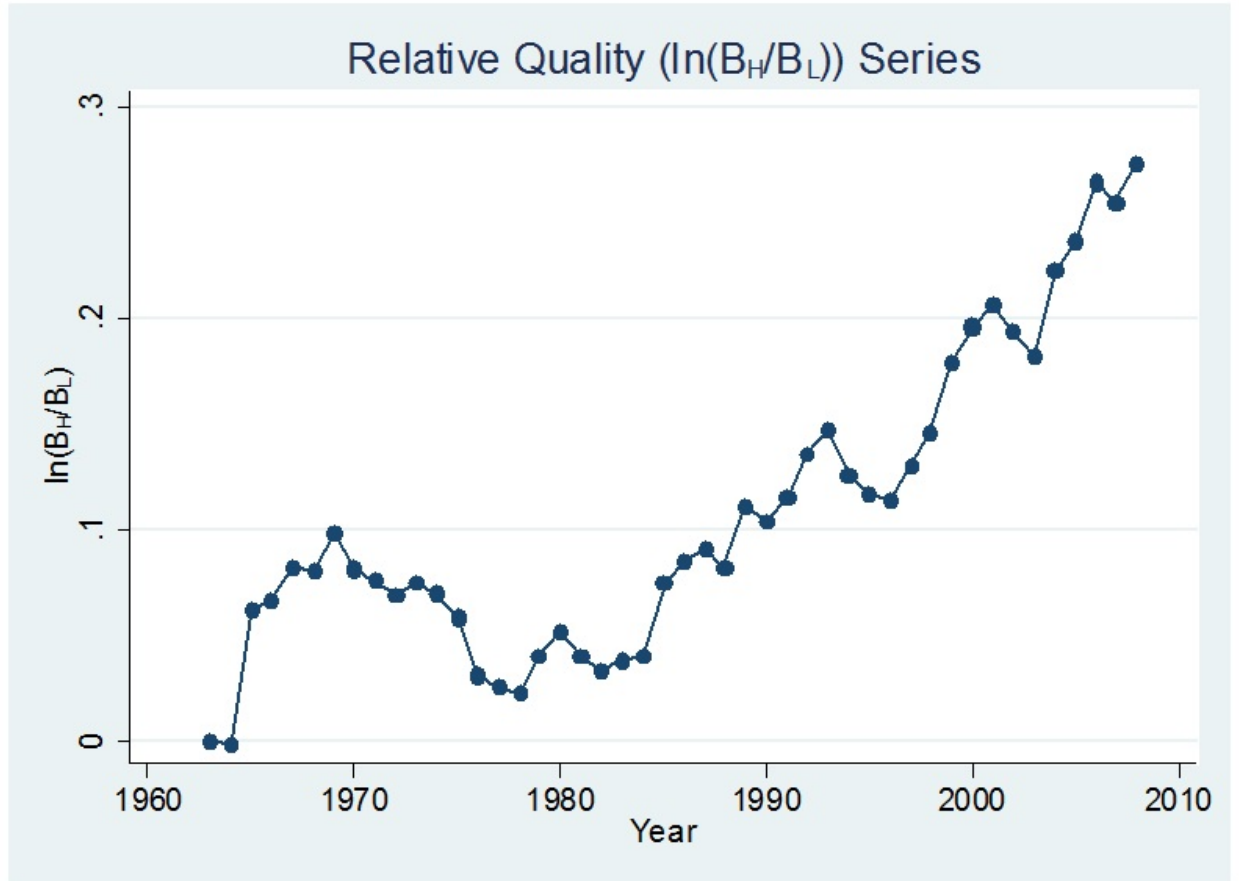

Figure 2

The path of $\ln \left(B_{H t} / B_{L t}\right)$ also creates a difference in the two measures of estimated relative supplies: the composition adjusted relative supplies, $\ln \left(H_{c t} / L_{c t}\right)$, and $\ln \left(H_{t} / L_{t}\right)$ obtained by dividing total relative wage payments by the BR relative price series. These are plotted together in Figure 3. Both measures show a strong increasing secular trend in the relative supply of skill. In the absence of demand shifts in favor of high skilled workers, this increased relative supply should have reduced the relative price ratio, in contrast with both series in Figure 1. The composition adjusted relative quantity measure, $\ln \left(H_{c t} / L_{c t}\right)$, is the same as Figure 2 in Acemoglu and Autor (2011) and shows a noticeable flattening starting in 1982. Estimated average annual growth in $\ln \left(H_{c t} / L_{c t}\right)$ declines from $4.37 \%$ over $1963-1982$ to only $1.91 \%$ from 1982 to $2008 .{ }^{17}$ The BR ratios, $\ln \left(H_{t} / L_{t}\right)$, show much less flattening in the early 1980s due to the increased relative per capita efficiency units for college graduates, $\ln \left(B_{H t} / B_{L t}\right)$.

\footnotetext{
${ }^{17}$ Card and DiNardo (2002) note that relative supply grew at a roughly constant annual rate of about $4.5 \%$ from 1967 to 1982, dropping to a much lower rate of about $2.0 \%$ from 1982-2000. They also report that a regression of the supply index on a linear trend and a post-1982 linear trend interaction has a $R^{2}$ of 0.997 .
} 




Figure 3

\subsection{Estimates from Parametric Canonical Models}

Figure 3 shows that the estimated skill ratio has increased substantially. This should have reduced the skill premium, but obviously did not as seen in Figure 1. The canonical framework accounts for the simultaneous increase in relative skill prices/wages and supplies by introducing SBTC through time-varying relative productivity constants $\ln \left(A_{H} / A_{L}\right)$. Empirically, the increased demand through SBTC must dominate the effects of rising relative skill supply.

An assumption must be made regarding the time trend for $\ln \left(A_{H} / A_{L}\right)$, since the technology coefficients are not directly observed. Furthermore, it is not possible to simultaneously estimate the elasticity of substitution $\sigma$ and to allow completely unrestricted year-to-year variation in $\ln \left(A_{H} / A_{L}\right)$. The simplest assumption, Katz and Murphy (1992), is that SBTC follows a linear trend: $\ln \left(A_{H t} / A_{L t}\right)=\gamma_{0}+\gamma_{1} t$. This linear trend specification and the assumption that relative human capital levels do not change within cells (i.e. $\ln \left(B_{H t} / B_{L t}\right)=0$ ) yields the standard estimating 
equation from the literature:

$$
\ln \omega_{c t}=\frac{\sigma-1}{\sigma} \gamma_{0}+\frac{\sigma-1}{\sigma} \gamma_{1} t-\frac{1}{\sigma} \ln \left(H_{c t} / L_{c t}\right) .
$$

Replicating Katz and Murphy (1992) for the 1963-1987 period, Acemoglu and Autor (2011) obtain the result:

$$
\ln \omega_{c t}=\alpha+0.027 t-0.612 \ln \left(H_{c t} / L_{c t}\right) .
$$

This simple specification captures the sharp reversal of the trajectory in relative log wages coinciding with the deceleration in the growth of relative skill supply in the late 1970s. The implied elasticity of substitution is $\sigma=\frac{1}{.612} \simeq 1.634$. SBTC increases the skilled wage premium by $2.7 \%$ per year. Table 1 reports estimation results using our data set that are analogous to those of Acemoglu and Autor (2011) and Katz and Murphy (1992), including the former's extension through 2008. ${ }^{18}$ Comparing columns 1 and 3 shows the marked difference in estimates for the elasticity of substitution and for the time trend using the extended period compared to the original Katz and Murphy (1992) period of 1963-1987. This is consistent with a poor out-of-sample fit using the parameters estimated on the original period to predict relative wage changes after 1987. Figure 4 shows this problem as highlighted in Autor, Katz and Kearney (2008). The prediction systematically deviates from the data, with a much larger predicted increase in relative wages after 1987 than actually occurs in the data.

Inspection of columns 1 and 3 in Table 1 shows that a linear time trend imposed over the full period results in a much higher estimated elasticity of substitution (2.955 vs. 1.598) and a much weaker SBTC time trend (1.64\% vs. 2.74\%). Autor, Katz and Kearney (2008) and Acemoglu and Autor (2011) explore more flexible specifications for SBTC to see whether they are better able to fit the data over the entire time period while producing reasonable estimates for $\sigma$. Columns 4 and 5 show identical results using our data. Column 4 allows for a break in the time trend at 1992, while column 5 allows for a more flexible (cubic) time trend throughout the period. These specifications produce a relatively stable elasticity of substitution, but the estimated time trends for SBTC imply that the relative demand for high skill workers decelerated in the 1990's, which Acemoglu and Autor (2011, p. 1109) argue "...does not accord with common intuitions regarding the nature or pace of technological change occurring in this era."

\footnotetext{
${ }^{18}$ We follow the procedure described in Acemoglu and Autor (2011) for construction of the variables and apply their sample selection criteria. The results reported in Table 1 are almost identical to those in Table 8 of Acemoglu and Autor (2011).
} 


\begin{tabular}{|c|c|c|c|c|c|}
\hline & \multirow{2}{*}{$\begin{array}{c}1963-1987 \\
(1)\end{array}$} & \multirow{2}{*}{$\begin{array}{c}1988-2008 \\
(2)\end{array}$} & \multicolumn{3}{|c|}{$1963-2008$} \\
\hline & & & (3) & (4) & (5) \\
\hline $\ln \left(H_{c} / L_{c}\right)$ & $\begin{array}{l}-0.6258 \\
(4.86)\end{array}$ & $\begin{array}{l}0.2853 \\
(1.96)\end{array}$ & $\begin{array}{l}-0.3384 \\
(7.88)\end{array}$ & $\begin{array}{l}-0.6454 \\
(9.87)\end{array}$ & $\begin{array}{l}-0.5590 \\
(5.95)\end{array}$ \\
\hline time trend & $\begin{array}{l}0.0274 \\
(5.08)\end{array}$ & $\begin{array}{l}0.0023 \\
(0.83)\end{array}$ & $\begin{array}{c}0.0164 \\
(12.61)\end{array}$ & $\begin{array}{l}0.0285 \\
(11.69)\end{array}$ & $\begin{array}{l}0.0197 \\
(3.58)\end{array}$ \\
\hline time $^{2} \times 100$ & . & . & . & . & $\begin{array}{l}0.0358 \\
(2.93)\end{array}$ \\
\hline time $^{3} \times 1000$ & . & . & . & . & $\begin{array}{l}-0.0069 \\
(4.37)\end{array}$ \\
\hline Post-1992 trend & . & . & . & $\begin{array}{l}-0.0102 \\
(5.45)\end{array}$ & . \\
\hline implied $\sigma$ & 1.598 & -3.505 & 2.955 & 1.549 & 1.789 \\
\hline $\begin{array}{l}\text { Demand Shift } \\
\text { Demand Shift }\end{array}$ & 0.0438 & -0.0080 & 0.0486 & & . \\
\hline $\begin{array}{c}1963-1992 \\
\text { Demand Shift } \\
1992-2008\end{array}$ & . & . & . & 0.0442 & . \\
\hline$R^{2}$ & 0.5680 & 0.9480 & 0.9348 & 0.9618 & 0.9600 \\
\hline TSS & 0.0231 & 0.0466 & 0.3930 & 0.3930 & 0.3930 \\
\hline $\mathrm{N}$ & 25 & 21 & 46 & 46 & 46 \\
\hline
\end{tabular}

Notes: Absolute value of t-statistics in parentheses

Table 1: Canonical Model Estimated Using Composition Adjusted Prices and Quantities

Estimating both SBTC and $\sigma$ using aggregate time series variation in relative wages and supplies is complicated by the absence of a direct measure of SBTC and the consequent identification problem. The results in column 2 of Table 1 highlight the challenges. Estimating the (linear trend) model on the post-1987 data yields the wrong sign for $\sigma$ and no evidence of SBTC. In fact, expanding the sample to use data from 1980 to 2008 makes things worse, producing a more negative and statistically significant value for $\sigma$. Unless the sample period includes enough pre-1980 data to cover both sides of the "break" in the trend for relative supplies, the estimate of $\sigma$ has the wrong sign. Even then, estimates of $\sigma$ are highly sensitive to the chosen sample period. Columns 4 and 5 fit the data over the full 1963-2008 period with a low $\sigma$ and a flexible path for SBTC that is fairly strong over most of the period.

We now show that standard estimates of $\sigma$ and SBTC are quite sensitive to the implicit maintained assumption that $\ln \left(B_{H t} / B_{L t}\right)$ is constant over time. This assumption can be relaxed, obtaining alternative estimates by using $\ln \omega_{t}$ and $\ln \left(H_{t} / L_{t}\right)$ from BR to directly estimate equation (5) 


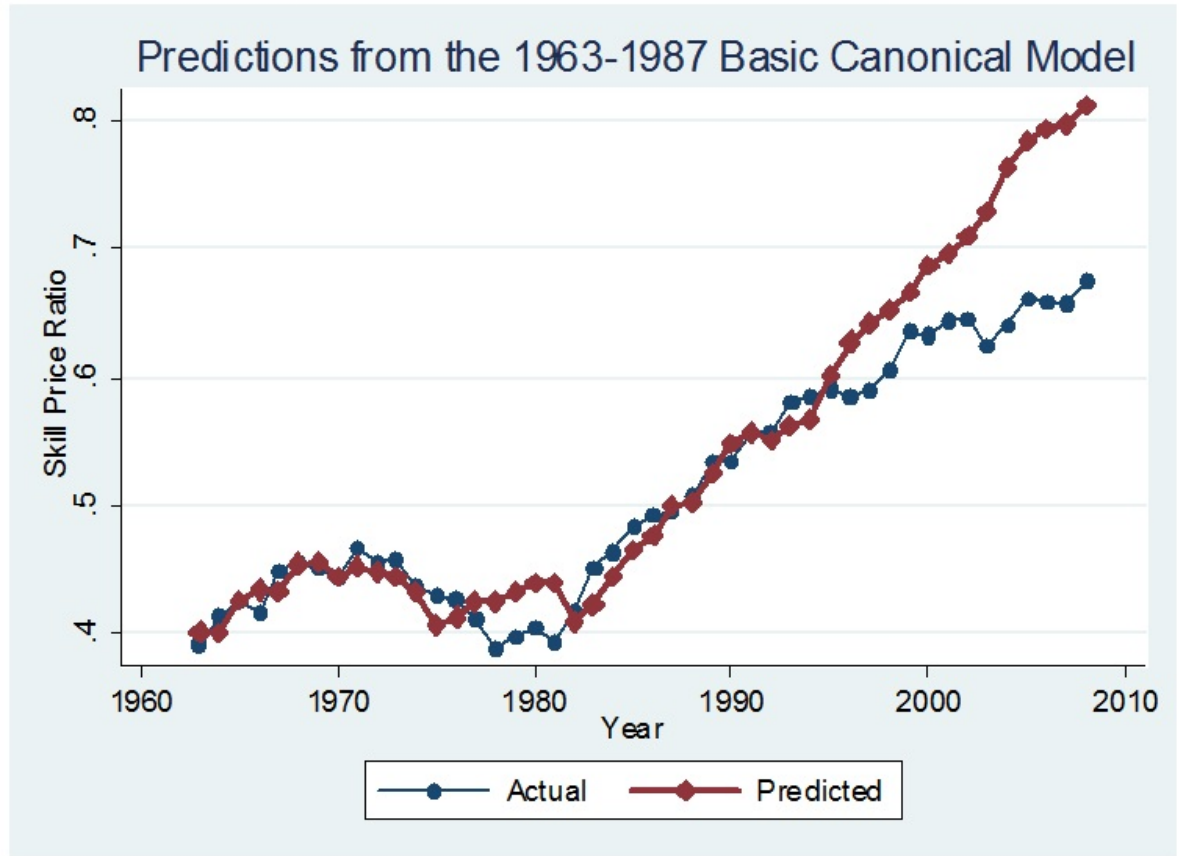

Figure 4

or by estimating the augmented model with $\ln \omega_{c t}$ and $\ln \left(H_{c t} / L_{c t}\right)$ while incorporating estimates of $\ln \left(B_{H t} / B_{L t}\right)$ over time as in equation (10). In both cases, parametric assumptions for SBTC can be made to match the previous literature. For example, in the simplest case of linear time trends, the estimating equation for the augmented model is

$$
\ln \omega_{c t}=\frac{\sigma-1}{\sigma} \gamma_{0}+\frac{\sigma-1}{\sigma} \gamma_{1} t+\frac{\sigma-1}{\sigma} \ln \left(B_{H t} / B_{L t}\right)-\frac{1}{\sigma} \ln \left(H_{c t} / L_{c t}\right) .
$$

The results from direct estimation of equation (5) using $\ln \omega_{t}$ and $\ln \left(H_{t} / L_{t}\right)$ (columns 1-3), and from estimating the augmented model equation (10) with $\ln \omega_{c t}$ and $\ln \left(H_{c t} / L_{c t}\right)$ and including $\ln \left(B_{H t} / B_{L t}\right)$ (columns 4-7) are reported in Table 2. Both approaches produce the same pattern of results. Notably, both produce much higher estimates of $\sigma$ and weaker demand growth from SBTC. Incorporating the cohort effects by estimating equation (5) directly, using $\ln \omega_{t}$ and $\ln \left(H_{t} / L_{t}\right)$ from BR eliminates problems with the wrong sign for $\sigma$ in any sub-period (columns 1-3). The point estimates for $\sigma$ range from 3.8-5.7 regardless of the sample period. However, the estimate is relatively imprecise for the post-1987 period. Estimates for $\sigma$ are roughly double those reported in Table 1, 


\begin{tabular}{|c|c|c|c|c|c|c|c|c|}
\hline & \multicolumn{3}{|c|}{ Direct Approach $(\ln \omega)$} & \multicolumn{5}{|c|}{ Augmented Model $\left(\ln \omega_{c}\right)$} \\
\hline & \multirow{2}{*}{$\begin{array}{c}1963-1987 \\
\text { (1) }\end{array}$} & \multirow{2}{*}{$\begin{array}{c}1988-2008 \\
(2)\end{array}$} & \multirow{2}{*}{$\begin{array}{c}1963-2008 \\
(3)\end{array}$} & \multirow{2}{*}{$\begin{array}{c}1963-1987 \\
(4)\end{array}$} & \multicolumn{4}{|c|}{$1963-2008$} \\
\hline & & & & & $(5)$ & (6) & & $(7)$ \\
\hline $\ln (H / L)$ & $\begin{array}{l}-0.1750 \\
(1.28)\end{array}$ & $\begin{array}{l}-0.2613 \\
(1.29)\end{array}$ & $\begin{array}{l}-0.2616 \\
(3.04)\end{array}$ & . & . & · & & . \\
\hline $\ln \left(H_{c} / L_{c}\right)$ & . & . & . & $\begin{array}{l}-0.3008 \\
(1.41)\end{array}$ & $\begin{array}{l}-0.1774 \\
(2.12)\end{array}$ & $\begin{array}{l}-0.2054 \\
(1.93)\end{array}$ & & $\begin{array}{l}-0.1955 \\
(6.02)\end{array}$ \\
\hline time & $\begin{array}{c}0.0074 \\
(1.29)\end{array}$ & $\begin{array}{c}0.0078 \\
(1.40)\end{array}$ & $\begin{array}{c}0.0043 \\
(0.89)\end{array}$ & $\begin{array}{l}0.0138 \\
(1.54)\end{array}$ & $\begin{array}{l}0.0098 \\
(2.99)\end{array}$ & $\begin{array}{l}-0.0006 \\
(0.10)\end{array}$ & & . \\
\hline time $e^{2} \times 100$ & . & . & $\begin{array}{c}0.0422 \\
(4.76)\end{array}$ & . & . & $\begin{array}{c}0.0574 \\
(5.27)\end{array}$ & & $\begin{array}{l}0.0582 \\
(8.48)\end{array}$ \\
\hline time $e^{3} \times 1000$ & . & . & $\begin{array}{l}-0.0069 \\
(6.34)\end{array}$ & . & . & $\begin{array}{l}-0.0092 \\
(6.73)\end{array}$ & & $\begin{array}{l}-0.0092 \\
(7.99)\end{array}$ \\
\hline $\ln \left(B_{H} / B_{L}\right)$ & . & . & $\cdot$ & $\begin{array}{l}0.4844 \\
(1.86)\end{array}$ & $\begin{array}{l}0.4148 \\
(2.21)\end{array}$ & $\begin{array}{c}0.6683 \\
(4.75)\end{array}$ & & $\begin{array}{l}0.6776 \\
(6.58)\end{array}$ \\
\hline implied $\sigma$ & 5.714 & 3.828 & 3.822 & 3.235 & 5.636 & 4.868 & & 5.115 \\
\hline $\mathrm{F}$ & $\cdot$ & . & $\cdot$ & 2.07 & 11.16 & 1.57 & & 1.63 \\
\hline $\operatorname{Prob}>F$ & & . & & 0.1645 & 0.0018 & 0.2175 & & 0.2084 \\
\hline$R^{2}$ & 0.0699 & 0.1209 & 0.8307 & 0.6292 & 0.9415 & 0.9744 & & 0.9744 \\
\hline TSS & 0.0040 & 0.0092 & 0.0403 & 0.0231 & 0.3930 & 0.3930 & & 0.3930 \\
\hline $\mathrm{N}$ & 25 & 21 & 46 & 25 & 46 & 46 & 46 & \\
\hline
\end{tabular}

Notes: Absolute value of t-statistics in parentheses. F reports the F-test statistic for the restriction from (12) that the difference between the coefficients on $\ln \left(B_{H} / B_{L}\right)$ and $\ln \left(H_{c} / L_{c}\right)$ equals 1 .

Table 2: Alternative Canonical Model Estimates

suggesting much greater substitutability between skill groups than previous estimates suggest. In addition, the estimated SBTC is substantially smaller than suggested by previous studies (Table 1).

This pattern is the same when cohort effects are incorporated using the augmented model estimated with composition adjusted wages and supplies, but also including $\ln \left(B_{H t} / B_{L t}\right)$. (The augmented model has a restriction that the difference in the estimated coefficients on $\ln \left(B_{H t} / B_{L t}\right)$ and $\ln \left(H_{c t} / L_{c t}\right)$ equals 1 . This restriction is not rejected using the F-test statistic reported in Table 2, except for column (5) where a linear time trend is assumed for the full period.)

Why are the results in Table 2 so different from those reported in Table 1? As shown in Figure 1, there is much less variation in relative prices, $\ln \omega_{t}$, than in relative wages, $\ln \omega_{c t}$. The weaker longrun increase in relative prices - due to improvements in the quality of skilled relative to unskilled workers as captured by $\ln \left(B_{H t} / B_{L t}\right)$ - means less SBTC is needed to explain the time series. A weaker correlation between deviations from trends in "true" relative prices and supplies compared 
to their composition adjusted counterparts is responsible for the larger estimates for $\sigma$ in Table 2 . Finally, the smaller early-1980's breaks in trends for both relative prices (Figure 1) and relative supplies (Figure 3), compared to their composition adjusted counterparts, produces more robust results across sub-periods when using the former (or when incorporating changes in $\ln \left(B_{H t} / B_{L t}\right)$ as in the augmented model).

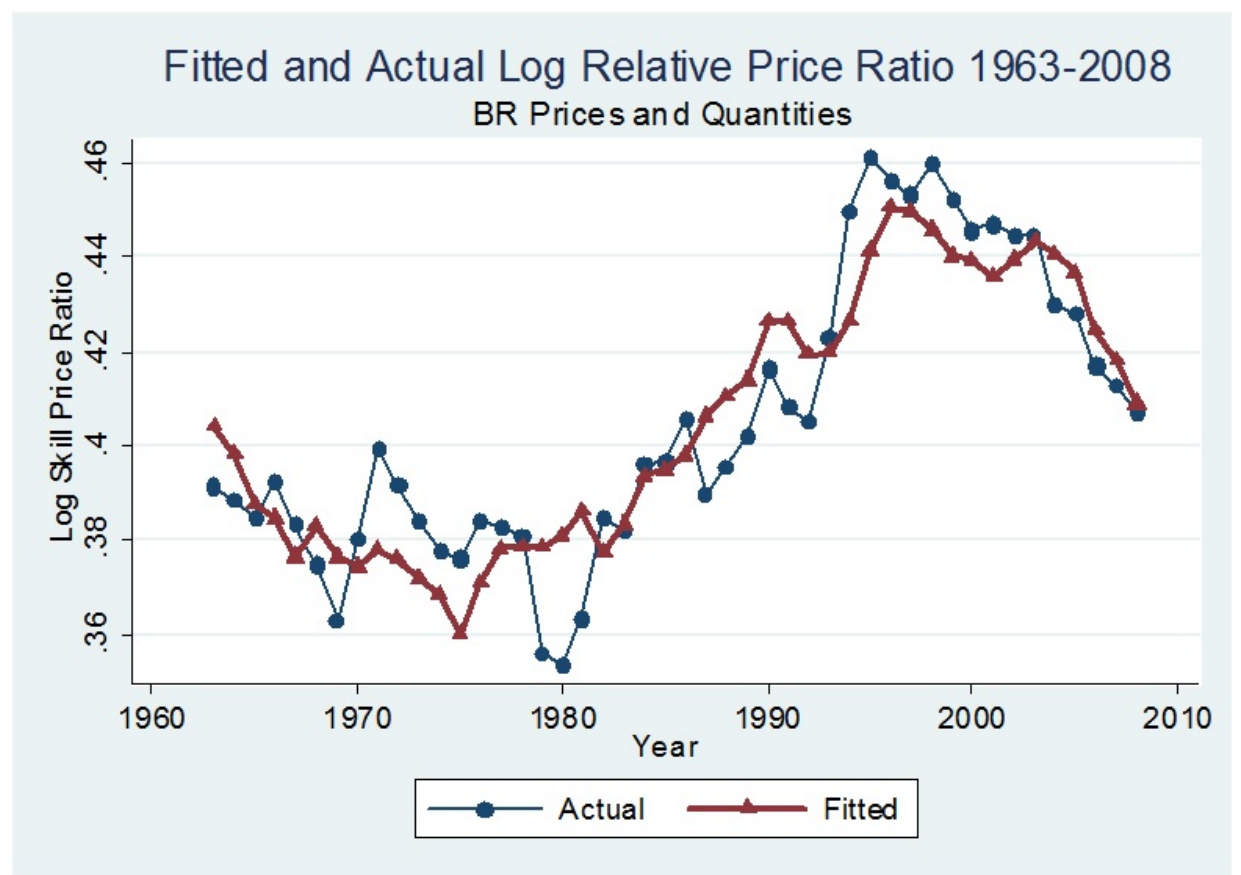

Figure 5

The direct approach models the skill price ratio, $\ln \omega_{t}$, rather than the wage premium, $\ln \omega_{c t}$. Figure 5 shows the excellent fit for the direct approach $\left(R^{2}=0.97\right)$ based on estimates using the full sample period (Table 2, column 7). The weaker SBTC and higher $\sigma$ provide a much-improved out-of-sample fit for the estimated model incorporating cohort effects relative to the basic model.

Now, consider out-of-sample prediction for the relative wage premium, $\ln \omega_{c t}$. Figure 6 plots the out-of-sample prediction for the augmented model using estimates from the 1963-1987 period (reported in column 4 of Table 2) along with the out of sample paths for $\ln \left(H_{c t} / L_{c t}\right)$ and $\ln \left(B_{H t} / B_{L t}\right)$. Using estimates from the direct approach for 1963-1987 (reported in column 1 of Table 2) to predict the relative skill price, $\ln \omega_{t}$, one can add the change in relative human capital levels per worker, 
$\ln \left(B_{H t} / B_{L t}\right)$, to calculate a predicted relative wage premium, $\ln \omega_{c t}$. This is also plotted in Figure 6. The out-of-sample fit for both models that incorporate cohort effects (with a simple linear trend for SBTC) is quite good for all but the last few years, in contrast to the poor out-of-sample fit for the basic model shown in Figure 4.

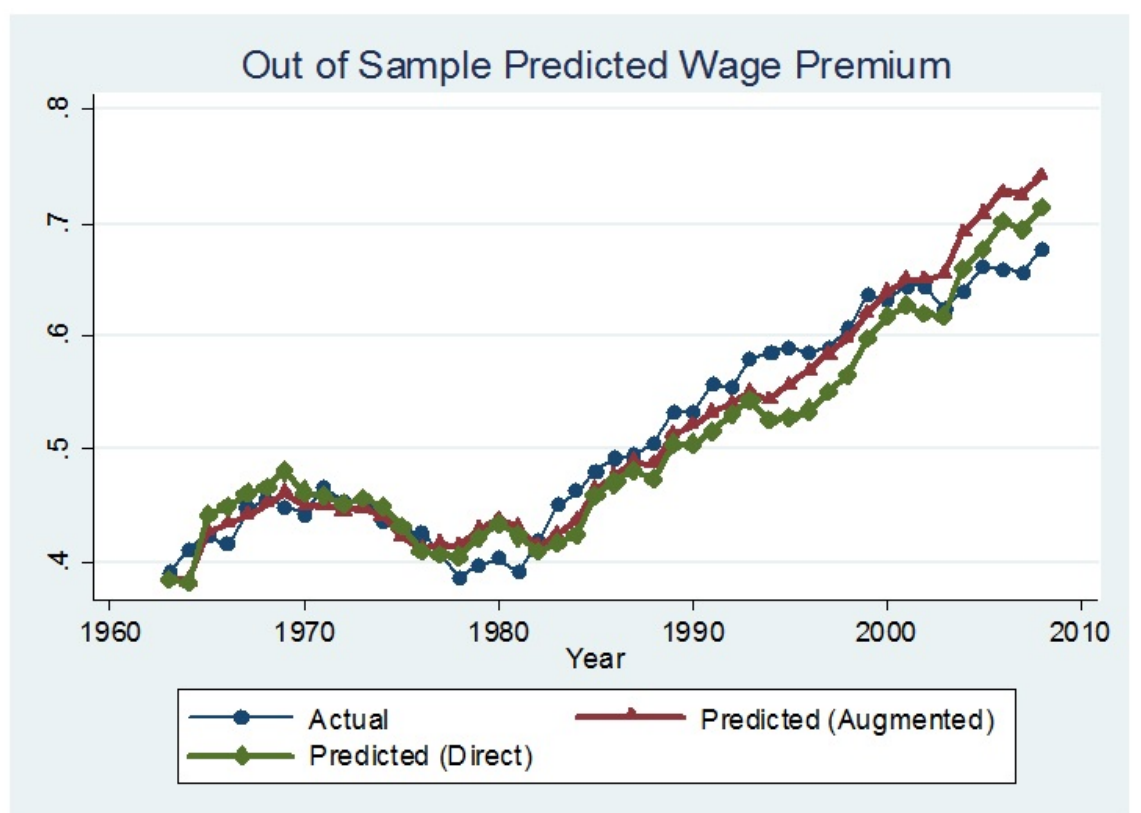

Figure 6

One concern with the direct approach is the potential bias introduced from using a regressor, $\ln \left(H_{t} / L_{t}\right)$, that is obtained by dividing the ratio of total wage payments by the BR relative price series, $\ln \omega_{t}$, which is the dependent variable. As a result, $\ln \left(H_{t} / L_{t}\right)$ is likely to be correlated with any measurement error in the BR relative price series. If the measurement error in the BR relative skill prices is classical, then the estimate of $\sigma$ will be biased towards $1 .{ }^{19}$ In fact, the estimates of $\sigma$ using the direct approach are quite similar to estimates from the augmented model, and both are much larger than estimates from the literature that completely ignores cohort differences in relative human capital levels within subgroups.

\footnotetext{
${ }^{19}$ See the Appendix for more details.
} 


\section{Is Imperfect Substitutability Across Experience Needed in the Canonical Model?}

Acemoglu and Autor (2011) argue that the basic canonical model is unable to explain important differences in the college wage premium by age or experience. In particular, Card and Lemieux (2001) point out that the rapid increase in the wage premium over the 1980s was almost exclusively confined to young age groups. Figure 7 plots the log composition adjusted relative wage ratio for young workers with 2-6 years of experience and older workers with 22-36 years of experience. As documented by Card and Lemieux (2001) and Acemoglu and Autor (2011), there is a very strong (more than $20 \log$ point) increase in the college wage premium for young workers over the 1980s, while the premium increased very little for older workers.

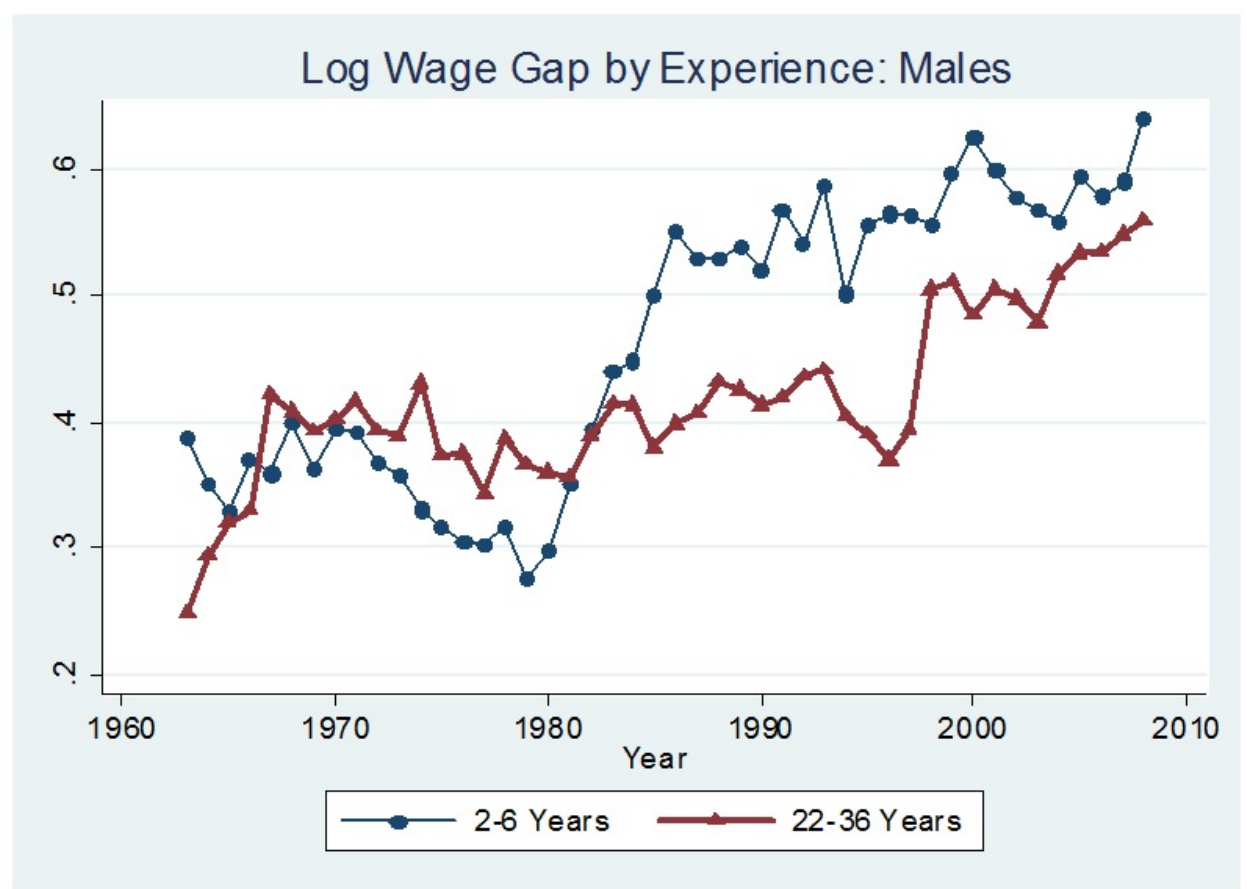

Figure 7

Card and Lemieux (2001), therefore, introduced imperfect substitutability across age groups within the original two broad skill input "types", estimating both the substitutability across skill types and across age groups within skill types. Acemoglu and Autor (2011) take a similar approach in introducing imperfect substitutability across experience groups within skill types. While their 
estimated elasticities of substitution across age groups (Card and Lemieux (2001)) or experience groups (Acemoglu and Autor (2011)) are high, they still help reconcile differences in the wage premium path by age or experience.

These studies, like the standard canonical model literature, rely on composition adjusted relative wages (and supplies), ignoring changes in relative worker quality/human capital over time. Yet, BR document much larger increases in the relative per worker human capital (high vs. low skill) over the 1980s for young workers compared to older workers. ${ }^{20}$ This rapid increase can be explained by the improvement in quality for college cohorts born over the 1950s (much more than in surrounding decades) due to a decline in college attendance rates. Consistent with this cohort quality explanation, the increase in college relative to high school skill levels that first appears for younger workers in the 1980s was followed roughly two decades later by a similar increase among older workers with 22-36 years of experience. This suggests that the more parsimonious canonical model, with perfect substitutability across age or experience groups, may provide a good approximation for wage patterns as long as cohort effects are taken into account. Put another way, the "problem" raised by Card and Lemieux (2001) and Acemoglu and Autor (2011) may be one of measurement more than a failure of the basic canonical model. ${ }^{21}$

To formalize this, it is useful to incorporate cohort effects disaggregated by age or experience groups, $j=1,2, . ., J$, into our framework. Replace the aggregate $B_{L t}$ and $B_{H t}$ terms of Section 3 with disaggregated $B_{L j t}$ and $B_{H j t}$ terms, where $L_{j t}=n_{j t} \bar{l}_{j t}, L_{c j t}=n_{j t} \bar{l}_{j}$, etc., and $B_{L j t}=L_{j t} / L_{c j t}$ and $B_{H j t}=H_{j t} / H_{c j t} .^{22}$ Composition adjusted wages for each experience group $j$ are given by $w_{L j t}^{c}=B_{L j t} w_{L j t}$ and $w_{H j t}^{c}=B_{H j t} w_{H j t}$, so:

$$
\ln \omega_{c j t}=\ln \omega_{j t}+\ln \left(B_{H j t} / B_{L j t}\right) .
$$

Even with perfect substitutability across experience groups, the time path of the wage premia may differ by experience group because of the $\ln \left(B_{H j t} / B_{L j t}\right)$ terms. ${ }^{23}$

\footnotetext{
${ }^{20}$ Also, see Heckman, Lochner and Taber (1998) for a similar point. They also emphasize the importance of adjustments in on-the-job human capital investment as a source of substantial wage fluctuations among younger workers.

${ }^{21}$ Carniero and Lee (2011) make a similar point. Accounting for cohort differences based solely on selection of ability among college students, they estimate an elasticity of substitution across age groups of roughly 10, much higher than the values estimated by Card and Lemieux (2001) and Accemoglu and Autor (2011).

${ }^{22}$ The $B_{L j t}$ and $B_{H j t}$ are the experience dis-aggregated components of the aggregate cohort effects represented by $B_{L t}$ and $B_{H t}$, respectively, in Section 3. $L_{j t}=n_{j t}\left(\bar{l}_{j}+l_{j t}^{d}\right)=L_{c j t}+n_{j t} l_{j t}^{d}$ and $B_{L j t}=1+\left(1 / L_{c j t}\right) n_{j t} l_{j t}^{d}$. When $l_{j t}^{d}=0$, $B_{L j t}=1$.

${ }^{23}$ These cohort effects may be introduced into the basic canonical model with imperfect substitutability by age (Card and Lemieux (2001)) or experience (Acemoglu and Autor (2011)) by incorporating the disaggregated $B_{L j t}$ and $B_{H j t}$ terms to create an augmented imperfect substitutability model. See the Appendix for more details.
} 


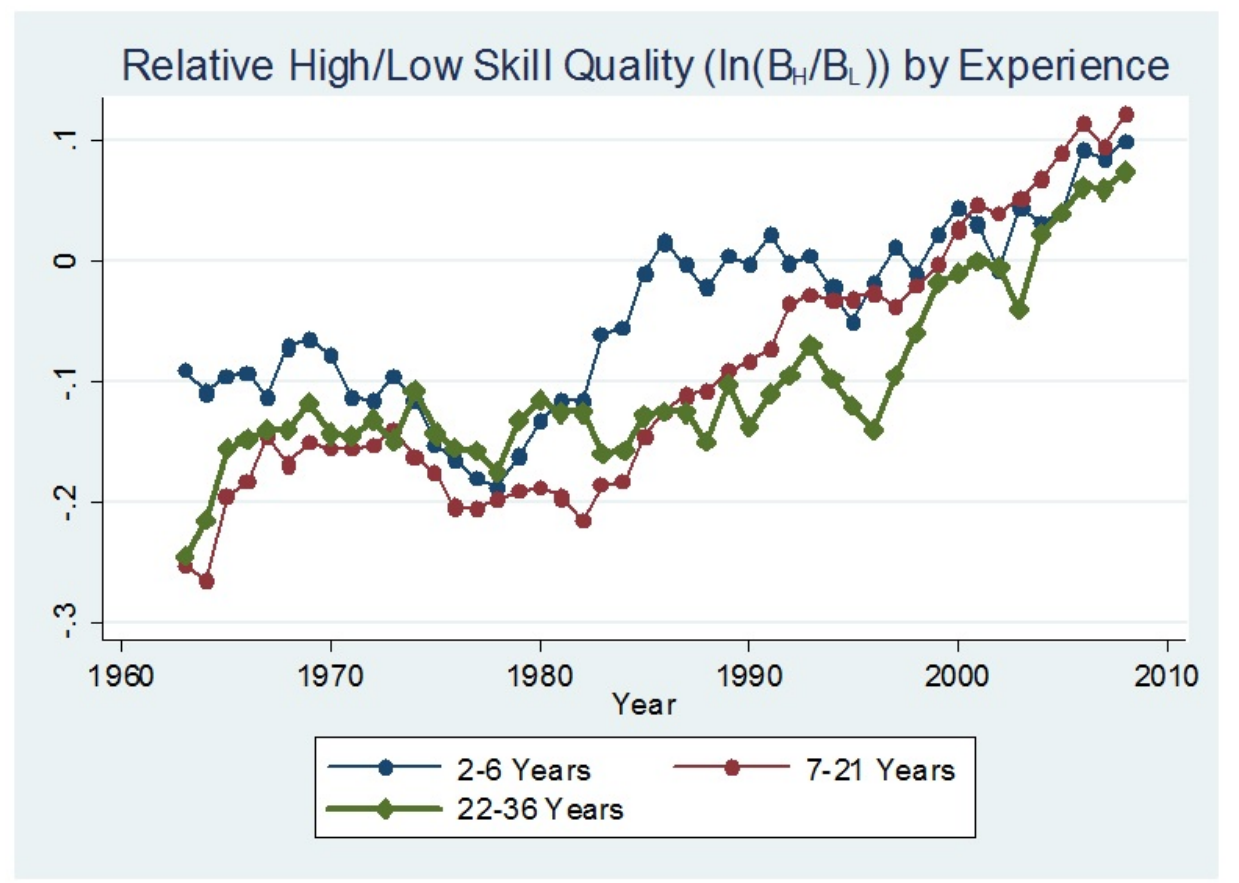

Figure 8

The disaggregated $\left(B_{H j t} / B_{L j t}\right)$ can be constructed analogously to the aggregate $\left(B_{H t} / B_{L t}\right)$ series in Section 3.1 using a comparison of the quantity ratios $\left(H_{j t} / L_{j t}\right)$ and $\left(H_{c j t} / L_{c j t}\right)$. The ratio $\left(H_{c j t} / L_{c j t}\right)$ is constructed as in Acemoglu and Autor (2011). The $\left(H_{j t} / L_{j t}\right)$ are obtained by dividing the ratio of the total wage payments $\left(W_{H j t} / W_{L j t}\right)$ by the price ratio $\left(w_{h t} / w_{L t}\right)$, where the skill prices are, as above, estimated from the wage changes of older workers (see Section 2.2). This implicitly assumes perfect substitutability across experience groups. Using these series, the derived paths for $\ln \left(B_{H j t} / B_{L j t}\right)$ show the expected qualitative differences by experience group. That is, a common price across experience groups for a given skill type produces series for $\ln \left(B_{H j t} / B_{L j t}\right)$ that are consistent with the evolution of college relative to high school worker quality as documented in BR and Carneiro and Lee (2011). See Figure 8, which plots $\ln \left(B_{H j t} / B_{L j t}\right)$ for three experience groups: 2-6 years, 7-21 years and 22-36 years. There is a much larger increase for the youngest relative to the oldest group over the 1980s, precisely when relative wages increased sharply for the younger but not the older group (Figure 7).

The younger group in Figure 8 (and Figure 7) in 1975 corresponds to 1945-1949 birth cohorts. 
These cohorts have the largest fraction of college graduates, suggesting strong negative selection effects on their per capita human capital. ${ }^{24}$ However, subsequent cohorts of college graduates improve as college enrolment rates decline (about 5 percentage points between 1950 and 1960 cohorts according to BR), implying increasingly positive selection (BR, Carneiro and Lee 2011). BR argue that there were also secular improvements in the production of human capital among the more recent cohorts. Altogether, they estimate an 11\% upward shift in the life-cycle human capital profile for college graduates between the 1949 and 1961 birth cohorts, much more than observed for cohorts born during the decades before or after.

Figure 8 further shows the increase in relative skill levels $\ln \left(B_{H j t} / B_{L j t}\right)$ over the 1950-1960 birth cohorts advance through the different experience groups as these cohorts age. The sharp increase in relative skill quality appears first for the youngest and least experienced workers in the late 1970s and 1980s, followed shortly by an increase among workers with 7-21 years of experience and finally by workers with 22-36 years of experience beginning in the late 1990s. Properly measuring relative skill prices by accounting for these cohort effects resolves much of the "puzzle" regarding differential college wage premiums by age or experience.

\section{The Importance of the Elasticity of Substitution: Endogenizing the Supply Response in the Canonical Model}

The elasticity of substitution, $\sigma$, and SBTC are the basic parameters of the canonical model. The results presented in Sections 3 and 4 suggest that the use of composition adjusted measures for the relative skill prices and quantities in the usual implementation of the canonical model results in a much lower value for $\sigma$, and a larger importance for SBTC than are obtained when these measures are corrected for cohort effects. A key secular trend in the US and many other countries over the last half century has been the increase in the relative supply of high skilled workers, largely through the increasing education levels. The response to this in the canonical model is governed by $\sigma$ : a high value of $\sigma$ dampens the response of relative wages. More generally, $\sigma$ is of major importance in determining the general equilibrium effects of any changes in the economy that affect the incentive to become a skilled worker through its role in governing the responsiveness of relative wages to

\footnotetext{
${ }^{24}$ Using state-level across cohorts, Carneiro and Lee (2011) show that cohorts with more students taking the SAT, which is strongly correlated with four-year college completion rates, have significantly lower average scores on the test. Similarly, test scores from the International Adult Literacy Survey among Americans with at least some college were lower for those from cohorts with higher college attendance rates.
} 
relative supply shifts. This section provides two examples of the importance of $\sigma$ in the context of endogenous relative supplies. First we show the sensitivity to alternative estimates of $\sigma$ within the framework of the canonical model. Second, we contrast the partial equilibrium effect of an increased subsidy to attend college that holds relative college and non-college wage rates constant with the general equilibrium effect that allows a supply response to an endogenized college premium response and show the sensitivity of the general equilibrium effect to the value of $\sigma$.

\subsection{SBTC, Relative Skill Supply and the Elasticity of Substitution}

Relative demand is given in Equation (4) and SBTC shifts the intercept in this relative demand, $(\sigma-1) \ln \left(A_{H} / A_{L}\right)$. This affects the skill premium, by shifting the intercept, $\frac{\sigma-1}{\sigma} \ln \left(A_{H} / A_{L}\right)$, in the skill premium Equation (5). Given $\sigma$, these two intercepts are proportional over time, where the factor of proportionality for the premium intercept relative to the demand intercept is $(1 / \sigma)$.

The overall path for relative wages, $\ln \omega_{c t}$, can be decomposed into the path for relative prices, $\ln \omega_{t}$, and the path for relative per capita college graduate quality (or human capital), $\ln \left(B_{H t} / B_{L t}\right)$, reflecting the overall cohort effects on the relative skill supply in any year. The path for relative prices, $\ln \omega_{t}$, is a net demand-supply effect determined by the "race" between relative supply growth and SBTC, resulting in a positive net demand-supply effect if SBTC dominates. Altogether, the wage premium decomposition can be written as:

$$
\ln \omega_{c t}=\ln \omega_{t}+\ln \left(B_{H t} / B_{L t}\right)=[\underbrace{\frac{\sigma-1}{\sigma} \ln \left(A_{H t} / A_{L t}\right)}_{\text {Demand }(S B T C)}-\underbrace{\frac{1}{\sigma} \ln \left(H_{t} / L_{t}\right)}_{\text {Supply }}]+\underbrace{\ln \left(B_{H t} / B_{L t}\right)}_{\text {Cohort quality }} .
$$

The decomposition of the relative wage premium, $\ln \omega_{c t}$, into the path of the net demand-supply effect (i.e. relative prices, $\left.\ln \omega_{t}\right)$ and the path of relative quality of the two skill types, $\ln \left(B_{H t} / B_{L t}\right)$, does not depend on the estimate of $\sigma .{ }^{25}$ However, the further decomposition of the path of the net demand-supply effect reflected in the relative prices into the path of the (positive) demand (SBTC) effects, $\left(\frac{\sigma-1}{\sigma} \ln \left(A_{H t} / A_{L t}\right)\right)$, and the (negative) supply effects, $\left(-\frac{1}{\sigma} \ln \left(H_{t} / L_{t}\right)\right)$, does depend on $\sigma$. We

\footnotetext{
${ }^{25}$ It just requires an estimate of $\ln \left(B_{H t} / B_{L t}\right)$ and the composition adjusted wage premium, $\ln \omega_{c t}$. Figure 2 in Section 3 plotted the series for $\ln \left(B_{H t} / B_{L t}\right)$ showing an important role for cohort effects in increasing the relative quality of the high skill type. The relative quality and net demand-supply components of $\ln \omega_{c t}$ are plotted together in the left panel of Figure A1. The large increase in the wage premium over the 1980-2000 period is driven in part by a sustained relative price increase over that period, but mainly by cohort effects that increased the relative per capita college graduate quality. The relative skill price declined from the late 1990s so that over the period as a whole the change in relative wages is driven largely by cohort effects reflected in the path of $\ln \left(B_{H t} / B_{L t}\right)$.
} 




Figure 9

consider the sensitivity of the estimated effects of SBTC on the wage premium to alternative assumed values for a constant $\sigma$ obtained from estimates with and without cohort effects. Figure 9 contrasts the path of the implied SBTC effect (the first term in the square bracket in equation (14)) under the assumption of $\sigma=4.868$ from the augmented model that accounts for cohort effects, with the path of the implied SBTC effects under the alternative assumption of $\sigma=1.789$ from the standard model that excludes cohort effects, reported in column (5) in Table 1. Both series are normalized to zero in 1963.

Unlike Tables 1 and 2, Figure 9 imposes no functional form on the estimates of SBTC and takes the value of $\sigma$ as given. However, Figure 9 shows, as expected from the parametric results in Tables 1 and 2, a much smaller role for SBTC using the higher value for $\sigma$. Over the full period, less than one percent a year of SBTC is required to offset the negative relative supply effect, since the effects of relative supply changes are muted when the elasticity of substitution is high. 


\subsection{The Elasticity of Substitution and General Equilibrium Effects of Education Policy}

Education policy can influence college attendance decisions in a variety of ways. This section considers policies equivalent to reductions in tuition, examining the partial and general equilibrium impacts of those policies with an emphasis on the importance of $\sigma$ for the latter. In principle, the same analysis applies to the effects of any changes that reduce the costs of going to college and increase the relative skill supply.

\subsubsection{College Attendance Decisions and the Human Capital Stocks}

Consider a standard lifecycle schooling choice model in which individuals choose whether to attend college with the objective of maximizing lifetime earnings (net of schooling costs). Individuals face two options at age 18: (i) work and receive earnings corresponding to the low skill (high school) human capital or (ii) go to college for four years and then work and receive earnings corresponding to the high skill (college) human capital. As in the canonical model of Section 2, there are only two skills. Using the notation of Section 2, the present value of low skill earnings associated with high school is given by:

$$
P V_{E}(h s)=\sum_{j=0}^{J_{L}} R^{-j} w_{L} l_{j}=w_{L} \theta_{L},
$$

where $J_{L}$ represents the number of years since leaving school (i.e. experience) to retirement for low skill workers, $l_{j}$ is the individual's low skill human capital at experience $j, w_{L}$ is the price of low skill

human capital, $R=(1+r)$ is the gross interest rate, and $\theta_{L} \equiv \sum_{j=0}^{J_{L}} R^{-j} l_{j}$. Similarly, the present value of high skill earnings associated with college are given by:

$$
P V_{E}(\text { coll })=\sum_{j=0}^{J_{H}} R^{-(j+4)} w_{H} h_{j}=w_{H} \theta_{H},
$$

where $J_{H}$ represents the number of years of experience to retirement for high skill (college) workers, $h_{j}$ is the high skill human capital of the college graduate at experience $j, w_{H}$ is the price of high skill human capital, and $\theta_{H} \equiv \sum_{j=0}^{J_{H}} R^{-(j+4)} h_{j}$.

In order to attend college, individuals must incur idiosyncratic costs. To simplify some of the expressions, represent the annual costs for individual $i$ at $j$ as a share $c_{j i}$ of lifetime low-skill earnings: 
$C_{j i}=w_{L} \theta_{L} c_{j i} \cdot{ }^{26}$ The present value of these costs is:

$$
C_{i} \equiv \sum_{j=0}^{3} R^{-j} C_{j i}=w_{L} \theta_{L} \phi_{i}
$$

where $\phi_{i}=\sum_{j=0}^{3} R^{-j} c_{j i}$. There is also a (common) subsidy for attending college with present value:

$$
S \equiv \sum_{j=0}^{3} R^{-j} S_{j}=s w_{L} \theta_{L}
$$

where $s$ is the subsidy rate expressed as a fraction of low skill earnings.

Assuming individuals are lifetime income maximizers who can freely borrow and lend, individual $i$ enrols in college if and only if

$$
P V_{E}(\text { coll })-C_{i}+S \geq P V_{E}(h s)
$$

or equivalently, if and only if:

$$
\phi_{i} \leq s+\omega \theta-1
$$

where $\theta \equiv \frac{\theta_{H}}{\theta_{L}}$, and $\omega$, as before, is the relative skill price, $w_{H} / w_{L}$. Assuming the density for the college cost parameter $\phi_{i}$ is given by $F(\phi)$ (with pdf $f(\phi)$ ), the fraction of individuals choosing college in any cohort is

$$
E(s, \omega)=F(s+\omega \theta-1) .
$$

As discussed further below, the college enrolment rate, $E(s, \omega)$, is increasing in the subsidy rate, $s$, and in the relative skill price, $\omega$.

Assuming all cohorts have a mass of $n$ and that individuals work for $J=J_{L}=J_{H}$ years regardless of their schooling, the steady state stocks of high and low skill human capital are given by:

$$
L=n \sum_{j=0}^{J} l_{j}[1-F(s+\omega \theta-1)] \quad \text { and } \quad H=n \sum_{j=0}^{J} h_{j} F(s+\omega \theta-1) .
$$

\subsubsection{Partial and General Equilibrium Response to Policy Changes}

Now consider a policy change to increase college enrolment by increasing the subsidy rate, $s$. The partial equilibrium response in the enrolment rate ignores any changes in the relative skill price, $\omega$, and is given by

$$
\Delta_{s}^{P E} \equiv \frac{\partial E(s, \omega)}{\partial s}=f(s+\omega \theta-1)
$$

\footnotetext{
${ }^{26}$ Similar results are obtained if direct costs of college are proportional to the price of high skill labor.
} 
This response would accurately measure the changes in enrolment for a small (random) subpopulation targeted by an increased subsidy rate. However, it does not reflect the total enrolment response for a policy administered to the full population. In the latter case, changes in enrolment rates (and, consequently, aggregate skill stocks $L$ and $H$ ) induced by the policy will lead to general equilibrium responses in relative skill prices (as discussed in Section 2), which feeds back into the enrolment decision (Heckman, Lochner and Taber 1998b). Due to the equilibrium relative price changes and their feedback effects on enrolment choices, the general equilibrium effects of a tuition subsidy policy will tend to differ from the partial equilibrium responses.

To characterize the full general equilibrium effect of a subsidy change, it is necessary to first show how the skill premium varies with the subsidy rate. This is easily done when comparing steady states. Substituting for the steady state aggregate stocks $H$ and $L$ (see equation (15)) into the skill premium equation (5) yields the equilibrium log relative skill premium implicitly defined as a function of $s$ (and other model parameters):

$$
\ln \omega(s)=\frac{\sigma-1}{\sigma} \ln \left(A_{H} / A_{L}\right)-\frac{1}{\sigma} \ln \left(\chi_{H} / \chi_{L}\right)-\frac{1}{\sigma} \ln \left(\frac{F(s+\omega(s) \theta-1)}{[1-F(s+\omega(s) \theta-1)]}\right),
$$

where $\chi_{H}=\sum_{j=0}^{J} h_{j}$, and $\chi_{L}=\sum_{j=0}^{J} l_{j}$. To simplify some of the expressions below, define $\tau \equiv$ $(s+\omega \theta-1)$. The marginal effect of a change in $s$ on relative skill prices can be obtained from implicit differentiation of equation (16) with respect to $s$ :

$$
\omega^{\prime}(s)=\frac{-\frac{1}{\sigma}\left[\frac{f(\tau)}{F(\tau)(1-F(\tau))}\right]}{\frac{1}{\omega}+\frac{1}{\sigma}\left[\frac{f(\tau)}{F(\tau)(1-F(\tau))}\right] \theta} \in\left(-\theta^{-1}, 0\right] .
$$

A larger tuition subsidy raises the college enrolment rate and the stock of high skill relative to low skill labor, which reduces the skill premium. This reduces the general equilibrium response of enrolment to a change in the subsidy rate.

Accounting for the relative skill price response, the full (steady state) general equilibrium response to an increase in $s$ is given by

$$
\Delta_{s}^{G E} \equiv \frac{d E(s, \omega(s))}{d s}=f(\tau)\left[1+\omega^{\prime}(s) \theta\right] \in(0, f(\tau)]
$$

The potential reduction in the earnings of high skill relative to low skill labor, $-1<\omega^{\prime}(s) \theta \leq 0$ (from equation (17), determines the magnitude of the general equilibrium offset to the partial equilibrium effect. Notably, $0<\Delta_{s}^{G E} \leq \Delta_{s}^{P E}$. 


\subsubsection{The Importance of $\sigma$ for General Equilibrium Responses}

The magnitude of the general equilibrium response relative to the partial equilibrium response depends critically on the elasticity of substitution between high skill and low skill labor, $\sigma$. To see this, take the ratio of the steady state general equilibrium effect to the partial equilibrium effect, substituting for $\omega^{\prime}(s)$ from equation (17):

$$
\frac{\Delta_{s}^{G E}}{\Delta_{s}^{P E}}=\frac{1}{1+\frac{1}{\sigma}\left[\frac{f(\tau)}{F(\tau)(1-F(\tau))}\right] \omega \theta}
$$

Based on this expression and rough estimates of $\omega \theta, f(\tau)$ and $F(\tau)$ from the literature, we next show that our estimated values for $\sigma$ lead to much larger general equilibrium enrolment responses to a tuition subsidy than would be predicted from previous estimates of $\sigma$.

Avery and Turner (2012) use the CPS to calculate the discounted present value of average earnings for high school and college graduates in the US. Their estimates for the 1980s-1990s suggest that college men earn around $\$ 1.2$ million over their careers, compared to $\$ 0.8$ million for male high school graduates. This suggests that $\omega \theta \approx 1.5$. The estimated response of college enrolment rates to changes in annual tuition/subsidies can be used to determine $f(\tau)$. Within the framework of this section, the partial equilibrium response to a discrete change in subsidies from $s$ to $s^{\prime}$ is:

$$
\operatorname{Pr}(\text { CollegeAttendance } \mid s)-\operatorname{Pr}\left(\text { CollegeAttendance } \mid s^{\prime}\right) \approx f(\tau)\left[s^{\prime}-s\right]
$$

Most of the literature suggests that a $\$ 1,000$ reduction in annual tuition would increase attendance rates in the range of $0.01-0.05 .{ }^{27}$ Since $s$ is the subsidy rate expressed as fraction of $w_{L} \theta_{L} \approx$ $\$ 800,000$, a $\$ 1,000$ change in the annual subsidy is equivalent to a change in $s\left(i . e . s^{\prime}-s\right)$ of roughly $4 \times \$ 1,000 / \$ 800,000=.005$. Assuming a change in the probability of attendance of 0.02 , this suggests $f(\tau) \approx \frac{.02}{.005}=4$. Finally, Bailey and Dynarski (2011) show that approximately $60 \%$ of cohorts born from 1970 to 1990 had completed at least some college. So we set $F(\tau) \approx 0.6$.

Implementation of the canonical model using the standard composition adjusted relative prices and quantities yields estimates of $\sigma$ around 1.5 - 1.8 (Table 1). Taking an intermediate value of $\sigma=1.6$ and using our back-of-the envelope calculations for $\omega \theta, f(\tau)$ and $F(\tau)$ in equation (18) yields

$$
\frac{\Delta_{s}^{G E}}{\Delta_{s}^{P E}}=0.060
$$

\footnotetext{
${ }^{27}$ See the surveys in Kane (2006) and Deming and Dynarski (2009).
} 
As discussed in Section 3, estimates of $\sigma$ based on the BR relative prices and quantities are at least double those of the previous literature (compare estimates in Tables 1 and 2). Using the smallest estimate of $\sigma=3.2$ from Table 2 yields

$$
\frac{\Delta_{s}^{G E}}{\Delta_{s}^{P E}}=0.110
$$

while a mid-range estimate of $\sigma=4$ yields

$$
\frac{\Delta_{s}^{G E}}{\Delta_{s}^{P E}}=0.138
$$

While the direct effect of the subsidy on enrolment is important, the elasticity of substitution is also a major determinant of the full general equilibrium response. ${ }^{28} \mathrm{~A}$ high elasticity implies a weaker supply response to policy, which results in smaller price adjustments and more similar general and partial equilibrium enrolment responses. In light of this, it is not surprising that the much higher elasticity obtained when accounting for cohort differences in skill levels (as estimated in this paper) produces general equilibrium enrolment effects that are roughly twice as large as those implied by previous estimates.

\section{Conclusion}

The standard implementation of the canonical model of wages and employment uses composition adjustment to construct "unit" wages and employment for low and high skilled labor. While this implementation of the model performed well for the 1963-1987 period studied in Katz and Murphy (1992), subsequent literature has pointed to a failure of the model to predict the aggregate college premium outside of this sample period or to predict the observed deviations in college premia for younger vs. older workers. This paper documents that these failings are due to mis-measurement of the relevant prices and quantities for low and high skill labor when using the standard composition adjustment methods, which ignore cohort effects that are particularly important in the 1980s and 1990s. Re-estimating the basic canonical model with prices and quantities that incorporate changes in skill levels across cohorts produces a much better fit for the out of sample prediction (from 1988

\footnotetext{
${ }^{28}$ Heckman, Lochner and Taber (1998b) examine partial and general equilibrium responses to a $\$ 500$ tuition subsidy financed by higher taxes on earnings. They also allow for heterogeneity in ability and do not link schooling costs directly to wage rates for high school graduates. While their framework is richer than here, they find a ratio of general equilibrium to partial equilibrium effects of similar magnitude: $\frac{\Delta_{s}^{G E}}{\Delta_{s}^{P E}}=0.087$.
} 
onward) and helps explain the observed deviation in the composition adjusted college premium for younger vs. older workers even with perfect substitutability across age or experience groups.

An important consequence of accounting for cohort effects is that the model implies a much higher elasticity of substitution between high and low skill labor than has been found in the standard literature that relies on composition adjusted measures. This has two significant implications. First, the higher estimated elasticity results in a much smaller role for SBTC in explaining the path of the college wage premium. Second, the elasticity of substitution is also an important parameter for the broader literature on education and wages, especially in assessing general equilibrium responses to government policies. For example, the relatively low elasticity of substitution estimated in previous studies of the canonical model implies large skill price responses to any change in the skill composition of the economy. In the case of a tuition subsidy, these price responses undo most of the direct (partial equilibrium) effect of the subsidy on enrolment, so that general equilibrium enrolment responses are substantially weaker (Heckman, Lochner and Taber (1998b)). By contrast, the higher elasticity obtained when accounting for cohort differences in skill levels, as estimated in this paper, produces much weaker general equilibrium relative price changes and stronger enrolment effects. 


\section{References}

[1] B. Abbott, G. Gallipoli, C. Meghir, and G.L. Violante. Education Policy and Intergenerational Transfers in Equilibrium. NBER Working Paper 18782, 2013.

[2] Daron Acemoglu and David Autor. Skills, Tasks and Technologies: Implications for Employment and Earnings. In Orley C. Ashenfelter and David Card, editors, Handbook of Labor Economics. North Holland, 2011.

[3] David H. Autor, Lawrence F. Katz, and Melissa S. Kearney. Trends in U.S. Wage Inequality: Revising the Revisionists. Review of Economics and Statistics, 90:300-323, 2008.

[4] Christopher Avery and Sarah Turner. Student Loans: Do College Students Borrow Too MuchOr Not Enough? Journal of Economic Perspectives, 26:165-192, 2012.

[5] Martha Bailey and Susan Dynarski. Inequality in Postsecondary Education. In G.J. Duncan and R.J. Murnane, editors, Whither Opportunity? Rising Inequality, Schools, and Childrens Life Chances. Russell Sage: New York, New York, 2011.

[6] Audra J. Bowlus, Haoming Liu, and Chris Robinson. Different Paths? Human Capital Prices, Wages and Inequality in Canada and the US. 2017. Working Paper.

[7] Audra J. Bowlus and Chris Robinson. Human Capital Prices, Productivity and Growth. American Economic Review, 102:3483-3515, 2012.

[8] David Card and John DiNardo. Skill-Biased Technological Change and Rising Wage Iequality: Some Problems and Puzzles. Journal of Labor Economics, 20:733-783, 2002.

[9] David Card and Thomas Lemieux. Can Falling Supply Explain the Rising Return to College for Younger Men? A Cohort Based Analysis. Quarterly Journal of Economics, CXVI:705-746, 2001.

[10] Pedro Carneiro and Sokbae Lee. Trends in Quality Adjusted Skill Premia in the United States: 1960-2000. American Economic Review, 101:2309-2349, 2011.

[11] David Deming and Susan Dynarski. Into college, out of poverty? policies to increase the postsecondary attainment of the poor. National Bureau of Economic Research Working Paper $15387,2009$. 
[12] Zvi Eckstein and Eva Nagypal. The Evolution of U.S. Earnings Inequality: 1961-2002. Federal Reserve Bank of Minneapolis Quarterly Review, 28(2):10-29, 2004.

[13] Claudia Goldin and Lawrence F. Katz. Long-Run Changes in the Wage Structure: Narrowing, Widening, Polarizing. Brookings Papers on Economic Activity, pages 135-165, 2007.

[14] James J. Heckman, Lance Lochner, and Christopher Taber. Explaining Rising Wage Inequality: Explorations with a Dynamic General Equilibrium Model of Labor Earnings with Heterogeneous Agents. Review of Economic Dynamics, 1:1-58, 1998.

[15] James J. Heckman, Lance Lochner, and Christopher Taber. Tax Policy and Human Capital Formation. American Economic Review, 88:293-297, 1998a.

[16] James J. Heckman, Lance Lochner, and Christopher Taber. General-Equilibrium Treatment effects: A Study of Tuition Policy. American Economic Review, 88:381-386, 1998b.

[17] Lutz Hendricks and Todd Schoellman. Student Abilities During the Expansion of US Education. Journal of Monetary Economics, 63:19-36, 2014.

[18] Thomas J Kane. Public intervention in post-secondary education.

[19] Lawrence Katz and David Autor. Inequality in the Labor Market. In Orley C. Ashenfelter and David Card, editors, Handbook of Labor Economics. North Holland, 1999.

[20] Lawrence Katz and Kevin Murphy. Changes in Relative Wages, 1963-1987: Supply and Demand factors. Quarterly Journal of Economics, 107:35-78, 1992.

[21] D. Lee and K.I. Wolpin. Intersectoral Labor Mobility and the Growth of the Service Sector. Econometrica, 74:1-46, 2006.

[22] Thomas Lemieux. Increasing Residual Wage Inequality: Composition Effects, Noisy Data, or Rising Demand for Skill? American Economic Review, 93(3):461-498, 2006.

[23] Jan Tinbergen. Substitution of Graduate by Other Labor. Kyklos, 27:217-226, 1974. 


\section{A Appendix}

\section{A.1 Measurement Error}

Suppose the relative price in BR is measured with error such that:

$$
\ln \omega^{m}=\ln \omega+\epsilon
$$

Since the relative skill quantity, $\ln (H / L)$, is obtained by dividing the total wage payment to $H$ relative to the total wage payment to $L$ by the relative price, the log relative skill quantity will also be measured with the same error, but opposite in sign:

$$
\ln (H / L)^{m}=\ln (H / L)-\epsilon
$$

This implies that estimating equation (5) is equivalent to estimating the model:

$$
\ln \omega^{m}=\alpha+\beta \ln (H / L)^{m}+(1+\beta) \epsilon
$$

where $\alpha=\frac{\sigma-1}{\sigma} \ln \left(A_{H} / A_{L}\right), \beta=-\frac{1}{\sigma}$ and $(1+\beta) \epsilon$ is (part of) the error term. Unless $\sigma=1$, classical measurement error for $\epsilon$ will bias $\sigma$ towards 1 , since $\operatorname{plim} \hat{\beta}$ is a weighted average of $\beta$ and -1 :

$$
\operatorname{plim} \hat{\beta}=\theta \beta+(1-\theta)(-1),
$$

where $\theta=\frac{\operatorname{Var}(\ln (H / L))}{\operatorname{Var}(\ln (H / L))+\operatorname{Var}(\epsilon)}$. As $\operatorname{Var}(\epsilon) \rightarrow 0, \operatorname{plim} \hat{\beta} \rightarrow \beta$.

\section{A.2 Incorporating Imperfect Substitution in the Canonical Model}

Imperfect substitution across experience is incorporated into the basic canonical model by Acemoglu and Autor (2011), analogously to the introduction of imperfect substitutability across age groups by Card and Lemieux (2001), by redefining the low $(L)$ and high $(H)$ type inputs as composites given by:

$$
L=\left[\sum_{j=1}^{J}\left(\alpha_{L j} L_{j}\right)^{\frac{\left(\sigma_{E}-1\right)}{\sigma_{E}}}\right]^{\frac{\sigma_{E}}{\left(\sigma_{E}-1\right)}}
$$

and

$$
H=\left[\sum_{j=1}^{J}\left(\alpha_{H j} H_{j}\right)^{\frac{\left(\sigma_{E}-1\right)}{\sigma_{E}}}\right]^{\frac{\sigma_{E}}{\left(\sigma_{E}-1\right)}}
$$


where $L_{j}$ and $H_{j}$ reflect the supplies of low and high skill, respectively, for experience group $j$, and $\sigma_{E}$ is the partial elasticity of substitution across experience groups within skill type. The different $\alpha_{L j}$ and $\alpha_{H j}$ reflect the different relative amounts of low and high skill for each experience group.

As shown in Card and Lemieux (2001), in this case the log skill premium can be written as:

$$
\ln \omega_{j}=\frac{\sigma-1}{\sigma} \ln \left(A_{H} / A_{L}\right)-\frac{1}{\sigma} \ln (H / L)+\frac{\sigma_{E}-1}{\sigma_{E}} \ln \left(\alpha_{H j} / \alpha_{L j}\right)-\frac{1}{\sigma_{E}}\left[\ln \left(H_{j} / L_{j}\right)-\ln (H / L)\right],
$$

where the coefficient on the log ratio of the aggregated supplies, $\ln (H / L)$, provides an estimate of $\frac{1}{\sigma}$ (elasticity of substitution between skill composites $L$ and $H$ ) and the coefficient on the deviation of the experience group specific supplies from the aggregated supplies, $\left[\ln \left(H_{j} / L_{j}\right)-\ln (H / L)\right]$, provides an estimate of $\frac{1}{\sigma_{E}}$ (elasticity of substitution between experience groups).

To incorporate the experience-specific cohort effects in the disaggregated canonical model, rewrite Equations (19) and (20) that incorporate these cohort effects as:

$$
L=\left[\sum_{j}\left(\alpha_{L j} B_{L j} L_{c j}\right)^{\frac{\sigma_{E}-1}{\sigma_{E}}}\right]^{\frac{\sigma_{E}}{\left(\sigma_{E}-1\right)}}
$$

and

$$
H=\left[\sum_{j}\left(\alpha_{H j} B_{H j} H_{c j}\right)^{\frac{\sigma_{E}-1}{\sigma_{E}}}\right]^{\frac{\sigma_{E}}{\left(\sigma_{E}-1\right)}} .
$$

Composition adjusted wages for each experience group $j$ are given by $w_{L j}^{c}=w_{L j} L_{j} / L_{c j}=B_{L j} w_{L j}$ and $w_{H j}^{c}=w_{H j} H_{j} / H_{c j}=B_{H j} w_{H j}$. Substituting these into equation (21), the augmented canonical model with imperfect substitutability across age or experience groups for the college wage premium is then:

$$
\begin{aligned}
\ln \omega_{c j}= & \frac{\sigma-1}{\sigma} \ln \left(A_{H} / A_{L}\right)-\frac{1}{\sigma} \ln (H / L)+\frac{\sigma_{E}-1}{\sigma_{E}} \ln \left(\alpha_{H j} / \alpha_{L j}\right)+\frac{\sigma_{E}-1}{\sigma_{E}} \ln \left(B_{H j} / B_{L j}\right) \\
& -\frac{1}{\sigma_{E}}\left[\ln \left(H_{c j} / L_{c j}\right)-\ln (H / L)\right] .
\end{aligned}
$$

Note that $\ln \left(B_{H j} / B_{L j}\right)$ plays exactly the same role as $\ln \left(\alpha_{H j} / \alpha_{L j}\right)$.

\section{A.3 Decomposition of the Relative Wage Premium}




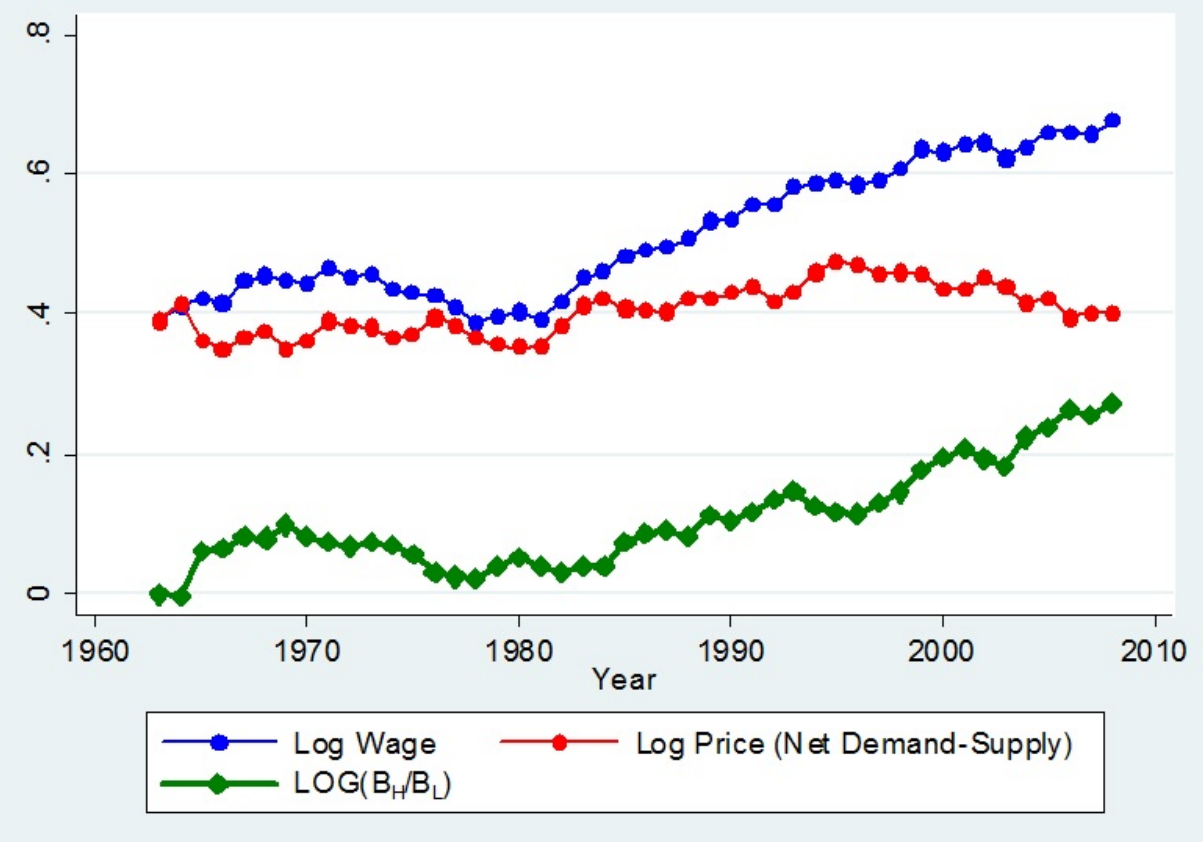

Figure A1 